\title{
Seasonal rates of benthic primary production in a Greenland fjord measured by aquatic eddy correlation
}

\author{
Karl M. Attard,1,2,* Ronnie N. Glud,1,2,3,4 Daniel F. McGinnis, 1,2,5,6 and Søren Rysgaard 2,4,7 \\ ${ }^{1}$ University of Southern Denmark, Nordic Centre for Earth Evolution (NordCEE), Odense, Denmark \\ ${ }^{2}$ Greenland Institute of Natural Resources, Greenland Climate Research Centre, Nuuk, Greenland \\ ${ }^{3}$ Scottish Association for Marine Sciences, Scottish Marine Institute, Oban, United Kingdom \\ ${ }^{4}$ University of Århus, Arctic Research Centre, Århus, Denmark \\ ${ }^{5}$ Helmholtz Centre for Ocean Research Kiel (GEOMAR), Kiel, Germany \\ ${ }^{6}$ Leibniz-Institute of Freshwater Ecology and Inland Fisheries (IGB), Berlin, Germany \\ ${ }^{7}$ University of Manitoba, Centre for Earth Observation Science, Clayton Riddell Faculty of Environment, Earth, and Resources, \\ Winnipeg, Manitoba, Canada
}

\begin{abstract}
We present the first year-round estimates of benthic primary production at four contrasting shallow (3-22 $\mathrm{m}$ depth) benthic habitats in a southwest Greenland fjord. In situ measurements were performed using the noninvasive aquatic eddy-correlation (EC) oxygen $\left(\mathrm{O}_{2}\right)$ flux method. A series of high-quality multiple-day EC data sets document the presence of a year-round productive benthic phototrophic community. The shallow-water sites were on average autotrophic during the spring and summer months, up to $43.6 \mathrm{mmol} \mathrm{O}_{2} \mathrm{~m}^{-2} \mathrm{~d}^{-1}$, and heterotrophic or close to metabolic balance during the autumn and winter. Substantial benthic gross primary production (GPP) was measured year-round. The highest GPP rates were measured during the spring, up to $5.7 \mathrm{mmol} \mathrm{O}_{2} \mathrm{~m}^{-2} \mathrm{~h}^{-1}\left(136.8 \mathrm{mmol} \mathrm{O}_{2} \mathrm{~m}^{-2} \mathrm{~d}^{-1}\right)$, and even at low light levels $\left(<80 \mu \mathrm{mol}_{\text {quanta }} \mathrm{m}^{-2} \mathrm{~s}^{-1}\right)$ during late autumn and winter we measured rates of up to $1.8 \mathrm{mmol} \mathrm{O}_{2} \mathrm{~m}^{-2} \mathrm{~h}^{-1}\left(43.2 \mathrm{mmol} \mathrm{O}_{2} \mathrm{~m}^{-2} \mathrm{~d}^{-1}\right)$ during peak irradiance. The benthic phototrophic communities responded seasonally to ambient light levels and exhibited year-round high photosynthetic efficiency. In situ downwelling irradiances as low as $\sim 2 \mu$ mol quanta $\mathrm{m}^{-2} \mathrm{~s}^{-1}$ induced an autotrophic response and light saturation indices $\left(I_{\mathrm{k}}\right)$ were as low as $11 \mu \mathrm{mol}$ quanta $\mathrm{m}^{-2} \mathrm{~s}^{-1}$ in the winter. On an annual timescale, the average areal rate of benthic GPP was $11.5 \mathrm{~mol} \mathrm{O}_{2} \mathrm{~m}^{-2} \mathrm{yr}^{-1}$, which is $\sim 1.4$ times higher than the integrated gross pelagic primary production of the $\sim 30-50 \mathrm{~m}$ deep photic zone of the fjord. These results document the importance of benthic photosynthesis on an ecosystem level and indicate that the benthic phototrophic compartment should be accounted for when assessing carbon and nutrient budgets as well as responses of coastal Arctic ecosystems to climate change.
\end{abstract}

Shallow-water environments constitute the most dynamic and productive ecosystems of the world's oceans (Middelburg and Soetaert 2004; Glud 2008). The productivity in shallow ecosystems is driven by both pelagic and benthic primary production. Despite this pattern, most studies focus on the pelagic environment alone and potentially ignore a considerable contribution from the benthic communities (Cahoon 1999). Furthermore, the presence of oxygen- $\left(\mathrm{O}_{2}\right)$ producing benthic microalgae alters the availability of biologically important solutes such as nitrate $\left(\mathrm{NO}_{3}^{-}\right)$, ammonium $\left(\mathrm{NH}_{4}^{+}\right), \mathrm{O}_{2}$, and carbon dioxide $\left(\mathrm{CO}_{2}\right)$ within the surface sediments as well as in the overlying water column (Fenchel and Glud 2000; Dalsgaard 2003). Benthic algae are in a prime location to benefit from the nutrients that are released from the sediment following mineralization of organic matter, and provided sufficient light is available they compete successfully with phytoplankton for the regenerated nutrients. In oligotrophic coastal waters benthic primary production therefore tends to dominate ecosystem production (Jahnke et al. 2000; Glud et al. 2002; Middelburg and Soetaert 2004).

The Arctic and subarctic regions are sparsely populated and only locally affected by eutrophication, but the region

\footnotetext{
* Corresponding author: karl.attard@biology.sdu.dk
}

is undergoing dramatic transformations. Changes in sea ice extent and thickness, precipitation and river discharge, and wind patterns alter the light and nutrient availability in the coastal zone and are expected to affect coastal productivity (Wassmann et al. 2011). While considerable research has focused on pelagic productivity in the Arctic, benthic primary production is surprisingly understudied (Glud et al. 2009). The extensive shelves of the Arctic Ocean encompass some $25 \%$ of the global shelf areas and may host a substantial biomass of benthic primary producers (Gattuso et al. 2006).

Rates of in situ benthic primary production are most often inferred from measurements of $\mathrm{O}_{2}$ exchange between the seabed and the overlying water column (termed the "benthic $\mathrm{O}_{2}$ exchange rate"; Glud 2008). Traditionally, the benthic $\mathrm{O}_{2}$ exchange rate has been quantified using benthic chambers and microprofilers. Transparent benthic $\mathrm{O}_{2}$ chambers enclose a known sediment area (typically $\sim 0.2 \mathrm{~m}^{2}$ ) and the areal exchange rate of $\mathrm{O}_{2}$ is inferred from the change in $\mathrm{O}_{2}$ concentration over time. Benthic $\mathrm{O}_{2}$ microprofilers provide point measurements of the $\mathrm{O}_{2}$ concentration gradient at the sediment-water interface to estimate the "diffusive benthic $\mathrm{O}_{2}$ exchange." Both methods are difficult to apply to hard benthic strata, which are widespread in Arctic and subarctic systems, and as a 
result large regions of the coasts remain severely understudied (Glud et al. 2010).

The introduction of the "aquatic eddy-correlation" (EC) technique for measuring benthic $\mathrm{O}_{2}$ fluxes by Berg et al. (2003) has made it possible to investigate the benthic $\mathrm{O}_{2}$ exchange rate under "true" in situ conditions. The EC technique infers the $\mathrm{O}_{2}$ exchange at the sediment-water interface from continuous Eulerian, high-frequency measurements of the flow velocity and $\mathrm{O}_{2}$ concentration taken at the same point within the benthic boundary layer (BBL) close to the sediment surface (Berg et al. 2003). This information is used to derive a continuous time series of vertical $\mathrm{O}_{2}$ fluxes across a horizontal plane. Since the EC measurements are carried out away from the sediment surface, the EC method is not confined to soft sediments. Importantly, EC fluxes integrate a large area of the seabed (typically $10-100 \mathrm{~m}^{2}$ ) under the natural light and flow conditions (Berg et al. 2007). To date, coastal applications of the EC technique constitute a limited but growing database. EC measurements on hard-bottom benthic surfaces (Glud et al. 2010), seagrass beds (Hume et al. 2011), permeable sediments (Berg et al. 2013), sea ice (Long et al. 2012), coral reefs (Long et al. 2013), and oyster beds (Reidenbach et al. 2013) document the validity of this method in environments where benthic chamber and microprofile measurements would be compromised.

The present study draws on the advantages of the EC method to estimate rates of benthic primary production and carbon turnover in shallow contrasting benthic ecosystems in a southwest Greenland fjord. We monitored these sites over a 13 month period to assess seasonal trends in the rates of benthic $\mathrm{O}_{2}$ exchange and inferred rates of benthic productivity from a series of multiple-day data sets. The objective of this study was to consider diel, day-to-day, as well as seasonal changes in benthic productivity, and to assess the ecological importance of benthic primary production in a vastly understudied region that is undergoing rapid climatic changes.

\section{Methods}

Study sites - The study was conducted between May 2011 and June 2012 within the Godthåbsfjord system in southwest Greenland (Fig. 1). A long-term monitoring program has been in place in Godthåbsfjord since 2006 with the aim to establish a long time series for key physical, chemical, and biological oceanographic observations (MarineBasis, www.nuuk-basic. $\mathrm{dk})$.

The EC system was deployed on a regular basis throughout the year at three locations nearby Nuuk, Greenland's capital city. Furthermore, we present a single deployment from a deeper fourth site. In all cases the EC system was lowered by hand from a small research vessel. Representative images from each of the four sites are shown in Fig. 2.

Site 1 was located in Nipisat Sound, a protected inlet with an area of around $3 \mathrm{~km}^{2}$. The EC system was placed in the inner part of the inlet at a depth of $3 \mathrm{~m}$ at mean low water. The flow in Nipisat Sound was tidally driven, with typical flow velocities ranging from 2 to $10 \mathrm{~cm} \mathrm{~s}^{-1}$ over a

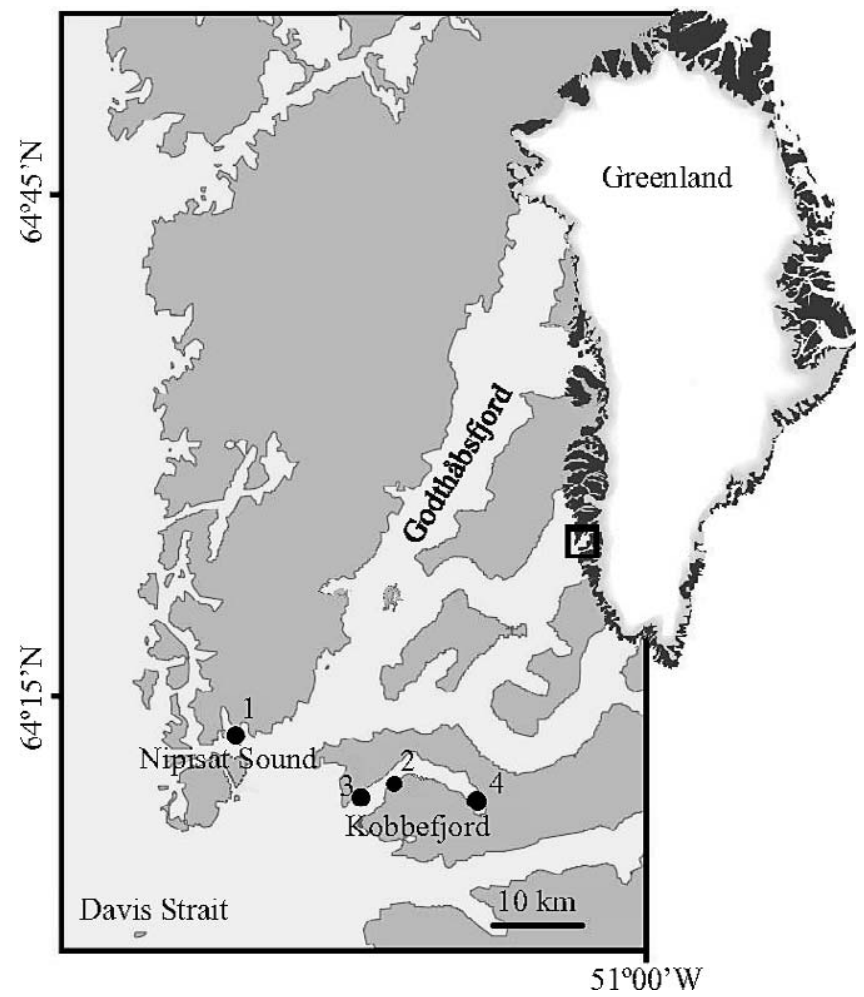

Fig. 1. Map indicating the location of our four study sites in Godthåbsfjord, southwest Greenland. Modified from Glud et al. (2010).

tidal cycle. The sediments in the sound were spatially heterogeneous, ranging from silty sands on the flanks to winnowed sands in the middle of the sound. Still and video imaging along with sediment sampling documented the presence of year-round benthic microalgae, while patches of filamentous green algae and small vascular brown macroalgae extending $2-10 \mathrm{~cm}$ up into the water column were present during the summer months. The sediment hosted dense infauna and epifauna communities dominated by polychaetes, bivalves, and echinoderms (Blicher et al. 2011). The inner regions of the sound were seasonally ice covered during the winter with a thickness of $\sim 10 \mathrm{~cm}$.

Sites 2, 3, and 4 were located within Kobbefjord, a wellconfined $25 \mathrm{~km}^{2}$ fjord close to the capital, Nuuk. Site 2 consisted of a sand flat with consolidated sands and gravels that extended for several hundred square meters within a depth range of 1-10 m. Benthic primary producers consisted mainly of benthic microalgae and filamentous green and small vascular brown macroalgae. The water velocity typically ranged from $1-6 \mathrm{~cm} \mathrm{~s}^{-1}$ over a tidal cycle.

Site 3 consisted of a rocky embayment ranging in depth from 1-7 m. The interstices between the rocks were filled with coarse gravels and relict shell fragments. Coralline red algae covered many of the rocks, and high densities of the urchin Strongylocentrotus droebachiensis were observed on the rocks as well as on the gravel interstices. The water velocity typically ranged from $1-4 \mathrm{~cm} \mathrm{~s}^{-1}$ over a tidal cycle.

Site 4 was located close to the head of Kobbefjord at a depth of $22 \mathrm{~m}$. The site was characterized by muddy sediments with occasional glacial drop stones encrusted in 


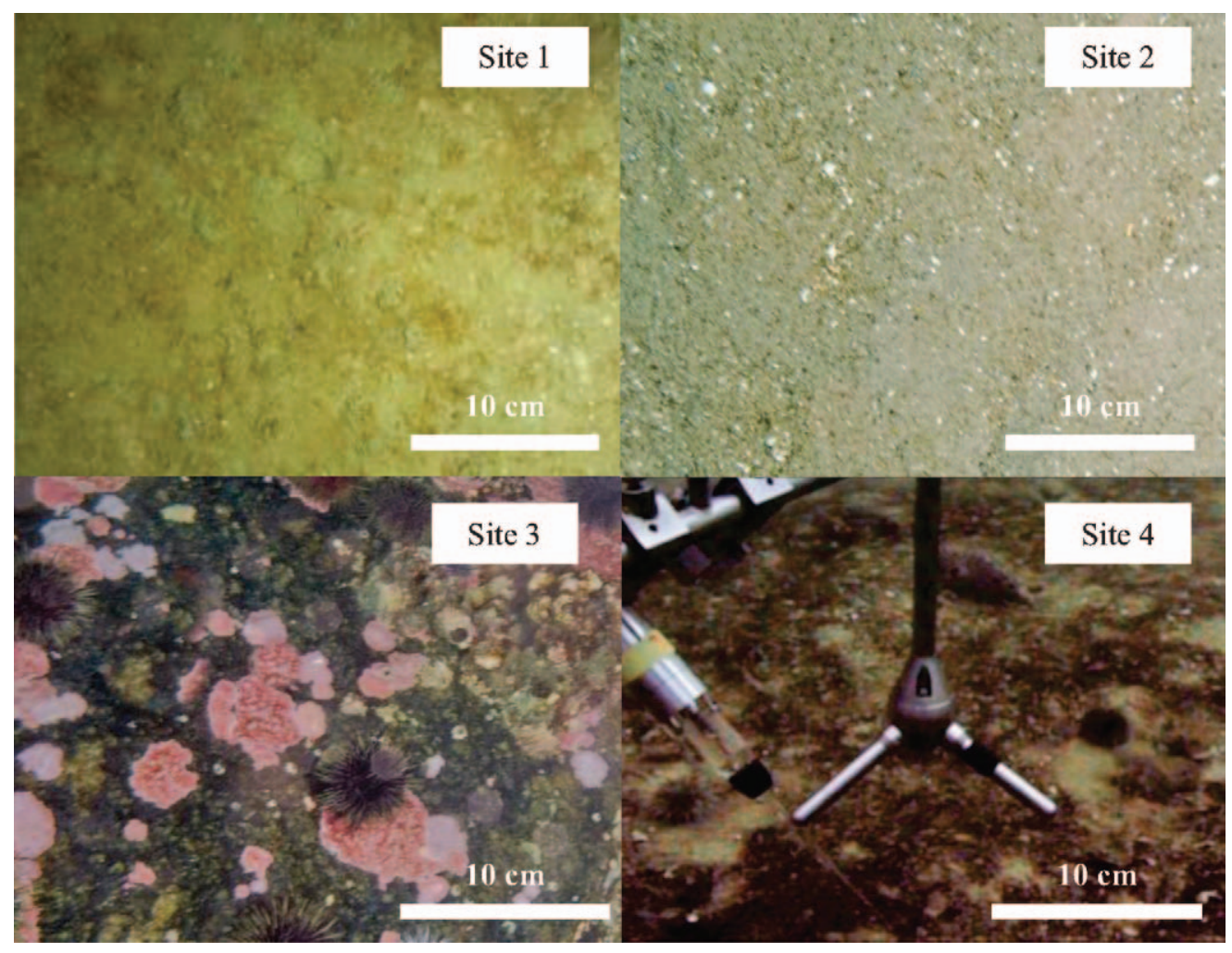

Fig. 2. The shallow sites investigated: (1) a muddy-sand embayment, (2) a sand-gravel embayment, (3) a rock-gravel embayment, and (4) a deeper muddy site. The images for sites 1-3 were obtained using a submersible camera with external strobes, while those for site 4 were taken with a small frame-mounted camera under natural light (hence the poorer quality). The image for site 1 is modified from Glud et al. (2010).

coralline algae. At the time of investigation (October 2011) large densities of the urchin S. droebachiensis were observed actively grazing on the microphytobenthic mat as well as on the coralline algae. The water velocity at this site ranged from $1-4 \mathrm{~cm} \mathrm{~s}^{-1}$.

EC measurements-The setup of the applied EC system was similar to the original design by Berg et al. (2003). The main components of the system consisted of an Acoustic Doppler Velocimeter (ADV; Vector, Nortek A.S.) and two parallel Clark-type $\mathrm{O}_{2}$ microsensors (10-20 $\mu \mathrm{m}$ tip diameter with a $90 \%$ response time $\leq 0.3 \mathrm{~s}$; Revsbech 1989) that relay the signal to the ADV via two custom-build submersible amplifiers (McGinnis et al. 2011). The deployment of two parallel $\mathrm{O}_{2}$ microsensors greatly increased our deployment success rate and provided an internal quality check of the $\mathrm{O}_{2}$ data (McGinnis et al. 2011).

The ADV recorded the streamwise $(u)$, traverse $(v)$, and vertical $(w)$ flow velocity components as well as the $\mathrm{O}_{2}$ microsensor data at frequencies of 32 or $64 \mathrm{~Hz}$ and in addition collected ancillary information such as instrument pitch and roll, flow direction, and signal strength. The equipment was mounted onto a stainless-steel tripod frame measuring $130 \mathrm{~cm} \times 90 \mathrm{~cm}$, designed to minimize hydrodynamic interference. The ADV was mounted downward-facing perpendicular to the seabed surface and the ADV sampling volume was located $25 \mathrm{~cm}$ above the sediment surface. This distance was at least 2 times larger than the stones, benthic epifauna, and other bottom features that we observed. The microsensor tips were carefully positioned at the edge of the ADV sampling volume to extract the $\mathrm{O}_{2}$ data close to the ADV measurement point without compromising the velocity measurements.

Our EC system was also equipped with a conductivitytemperature-depth (CTD) sensor (SBE 19 plus V2, Seabird). Apart from the standard suite of sensors, the CTD had a downwelling photosynthetically active radiation (PAR) sensor (QCP-2000, Biospherical Instruments) and an $\mathrm{O}_{2}$ optode (4340, Aanderaa). This instrument provided continuous measurements of the environmental parameters covering each EC deployment at a resolution of 60 or $120 \mathrm{~s}$.

Prior to deployment, the $\mathrm{EC} \mathrm{O}_{2}$ microsensors were left to polarize for $10-12 \mathrm{~h}$ to minimize sensor drift during deployments. A preliminary calibration of the sensors was carried out using two water samples of known $\mathrm{O}_{2}$ concentration at in situ temperature and salinity. A sodium dithionite solution was used for the zero $\mathrm{O}_{2}$ saturation value, and collected bottom-water samples at the measuring site were used for the in situ saturation value. The $\mathrm{O}_{2}$ concentration was later determined in the laboratory by Winkler titration. In total, 18 successful deployments were made during our 13 month measurement campaign, with the deployment time ranging from 20 to $119 \mathrm{~h}$ with a total 
of $\sim 750 \mathrm{~h}$ and an overall deployment average of $41 \mathrm{~h}$. Unfavorable sea ice conditions persisted during spring 2012 and prevented access to the sites in Kobbefjord, limiting our observations during this period.

EC fluxes-The EC $\mathrm{O}_{2}$ fluxes were first extracted from the raw EC data set and then evaluated for their "quality" based on a set of defined criteria. Flux extraction was carried out using the software package Sulfide Oxygen Heat Flux Eddy Analysis (SOHFEA) version 2.0 (available from www.dfmcginnis.com/SOHFEA). SOHFEA employs a protocol for flux extraction that is very similar to the one described by Lorrai et al. (2010). Additional data treatments that are detailed below but not available in SOHFEA were carried out in MATLAB ${ }^{\circledR}$ (MathWorks). The data sets were processed for flux extraction in the following order: (1) Weak signals in the raw 32 or $64 \mathrm{~Hz}$ ADV velocity data were identified by a low beam correlation and/or low signal strength. Individual data points with beam correlations below $70 \%$ and signal-tonoise ratios below $12 \mathrm{~dB}$ were discarded. These thresholds were lowered to $50 \%$ and $10 \mathrm{~dB}$, respectively, during the winter months, when the particle density in the water was greatly reduced. (2) The 32 or $64 \mathrm{~Hz}$ raw EC data were averaged down to $8 \mathrm{~Hz}$. This reduced the noise level and the smaller file size allowed for easier data handling. (3) A spectral analysis was carried out on the $8 \mathrm{~Hz}$ vertical velocity $(w)$ and the $\mathrm{O}_{2}$ microsensor data $(C)$. The spectra showed the presence of an inertial subrange, identified as the region on the pressure spectral density plot for $w$ and $C$ where the slope of energy cascade to the smaller scales followed the predicted $-5 / 3$ fit, suggesting well-developed turbulence. The spectra furthermore revealed that the data reduction through adjacent averaging from 64 or $32 \mathrm{~Hz}$ to $8 \mathrm{~Hz}$ did not result in a loss of signal at high frequency, since most of the turbulent contributions typically occurred at a frequency of $2 \mathrm{~Hz}$ or lower. (4) The $\mathrm{O}_{2}$ microsensors were calibrated to the CTD $\mathrm{O}_{2}$ optode data. (5) Spike noise in the velocity and $\mathrm{O}_{2}$ microsensor data were removed using the three-dimensional phase space method by Mori et al. (2007). (6) The measured $8 \mathrm{~Hz}$ ADV velocity data set was rotated using the "planar rotation" method to obtain a vertical velocity component that is normal to the local streamline (Lorke et al. 2013). Rotation of the data set is required to exclude vertical projections of the horizontal velocity components that may arise from a slight tilt in the instrument or from topographic features. (7) The $\mathrm{O}_{2}$ fluxes, in mmol m $\mathrm{m}^{-2} \mathrm{~h}^{-1}$, were extracted from the ADV velocity and $\mathrm{O}_{2}$ microsensor data as the covariance $w^{\prime} C^{\prime}$, where $w^{\prime}$ and $C^{\prime}$ are deviations from a least-squares linear trend fitted to the measured vertical velocity and $\mathrm{O}_{2}$ concentration, respectively, and the angle bracket denotes time averaging. Following Reynolds decomposition theory the vertical velocity vector may therefore be expressed as $w=w$ $+w^{\prime}$ and the scalar quantity $C=C+C^{\prime}$ (Berg et al. 2003). The selected time averaging interval is a tradeoff between including as many of the flux-contributing turbulent eddies as possible while excluding low-frequency nonturbulent contributions such as advective flows that may compromise covariance statistics (McGinnis et al. 2008). To determine

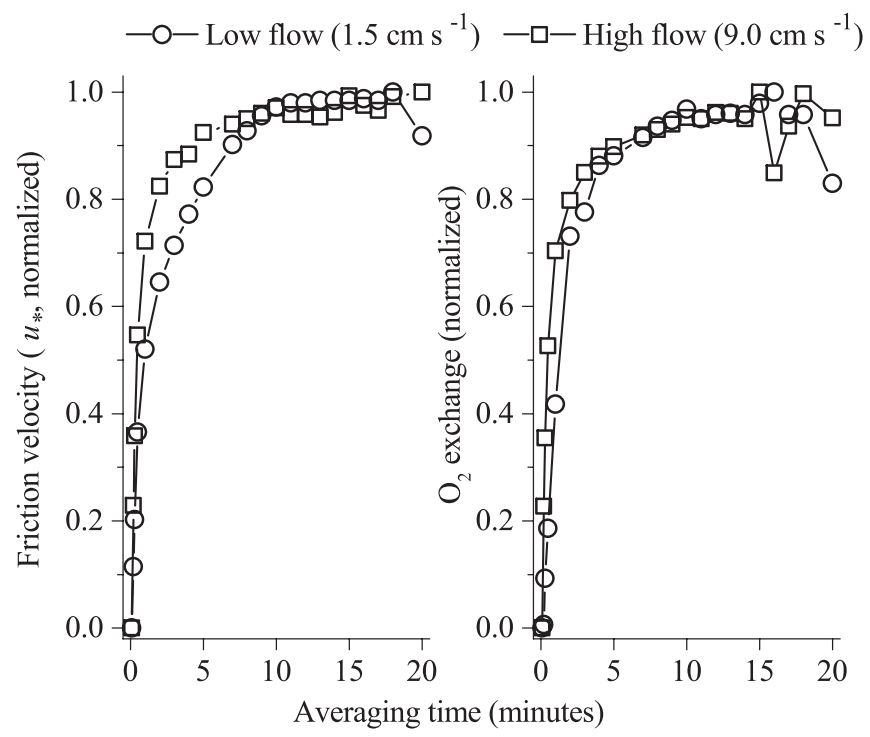

Fig. 3. The analysis carried out to investigate the effects of averaging time on the mean covariance and subsequent flux estimates for the friction velocity $\left(u_{*}\right)$ and the $\mathrm{O}_{2}$ fluxes. The selected time interval of $10 \mathrm{~min}$ is a tradeoff between including as many of the flux-contributing eddies as possible while excluding low-frequency nonturbulent contributions.

the optimal time interval, an analysis was carried out to investigate the effects of averaging time on the mean covariance and subsequent flux estimates for the friction velocity $\left(u_{*}\right)$ and the $\mathrm{O}_{2}$ fluxes. The $u_{*}$ is directly related to the turbulence regime within the BBL. Estimates for $u_{*}$ were computed from complex Reynolds stress measurements derived from the ADV velocity time series (McPhee 2008). The streamwise $(u)$, traverse (v), and vertical $(w)$ velocity components were decomposed into a mean and deviatory velocity as $u=\langle u\rangle+u^{\prime}, v=\langle v\rangle+v^{\prime}$, and $w=$ $<w>+w^{\prime}$. The $u_{*}$ was then calculated as $u_{*}=\left(u^{\prime} w^{\prime 2}+\right.$ $\left.v^{\prime} w^{\prime 2}\right)^{1 / 4}$. The mean $u_{*}$ and $\mathrm{O}_{2}$ flux were computed as a function of the ensemble average for periods of both low and high flow velocity magnitude. A time window of $10 \mathrm{~min}$ was consistently identified as the optimal interval for flux calculation at the four sites (Fig. 3). (8) A time-shift correction was applied to the data. Time shifting was performed for each ensemble interval by shifting the $\mathrm{O}_{2}$ data in time relative to the velocity data to a maximum of $2 \mathrm{~s}$ to achieve the maximum correlation (defined in terms of the maximum flux) for $w^{\prime} C^{\prime}$. This correction is necessary when the physical separation between the $\mathrm{O}_{2}$ sensor and the ADV measurement volume, and/or the sensor response time, result in a slight misalignment in the data (McGinnis et al. 2008). (9) By assuming law-of-the-wall velocity profiles, the mean sediment surface roughness $\left(z_{0}\right)$ was estimated as $z_{0}=z \times \exp \left(-\kappa \times\left[U / u_{*}\right]\right)$, where $z$ is the measurement height above the benthic surface $(0.25 \mathrm{~m}), \kappa$ is the von Karman constant (0.41), and $U$ is the flow velocity magnitude. (10) The coefficient of drag $\left(\mathrm{C}_{\mathrm{D}}\right)$ was computed as $C_{D}=u_{*}^{2} / U^{2}$ (McPhee 2008).

The extracted 10 min EC fluxes were then evaluated for their quality based on three criteria, namely: (1) collisions of particles or debris with the $\mathrm{O}_{2}$ microsensor (spikes), (2) 


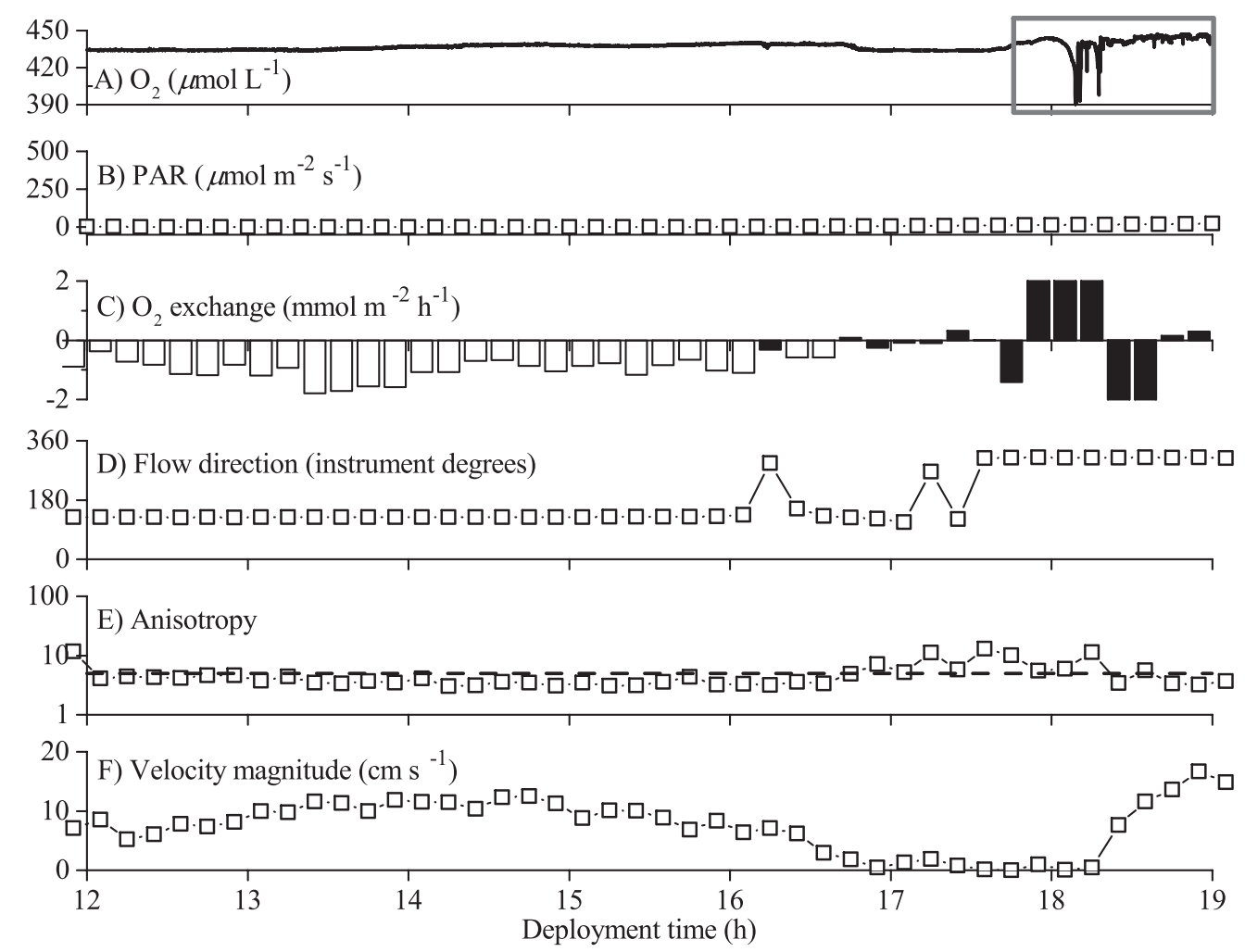

Fig. 4. The derived 10 min $\mathrm{EC} \mathrm{O}_{2}$ exchange rates were evaluated for quality based on three criteria, namely (1) collisions of particles or debris with the $\mathrm{O}_{2}$ microsensor, (2) rapid changes in flow direction, and (3) the level of anisotropic turbulence, computed as the ratio between the horizontal and vertical dissipation rate of turbulent kinetic energy $(\varepsilon)$. (F) Periods with low flow were typically characterized by (E) high anisotropic ratios and (C) suppressed exchange rates of $\mathrm{O}_{2}$, indicating that eddy theory may not hold during these periods. (E) The broken line $(y=5)$ indicates the threshold ratio used to exclude data. (A) The gray box indicates the section of $\mathrm{O}_{2}$ data that was compromised possibly due to debris hitting and getting attached to the sensor. (C) The black bars indicate the 10 min exchange rates that were excluded due to one or more violations in the three screening criteria. Altogether the screening process typically resulted in $<20 \%$ of the data being excluded.

rapid changes in flow direction, and (3) the level of anisotropic turbulence, computed as the ratio between the horizontal and vertical dissipation rate of turbulent kinetic energy $(\varepsilon)$. We estimated the $\varepsilon$ using the inertial subrange method by Bluteau et al. (2011), which is independent of law-of-the-wall scaling. Typically, stratification buildup under periods of low flow velocity reduces vertical turbulent mixing to a greater extent relative to the horizontal counterpart. The $\mathrm{O}_{2}$ fluxes as measured by EC are seen to be highly suppressed, indicating that turbulence transport is also severely suppressed, and the eddy assumptions are no longer valid (Brand et al. 2008). The threshold anisotropy ratio used to filter $\mathrm{EC}_{2}$ fluxes was typically $5-15$, although it varied between sites and between individual deployments. Altogether the screening process based on the three criteria typically filtered out $<20 \%$ of the measured 10 min $\mathrm{EC} \mathrm{O}_{2}$ fluxes. An example of how factors like low flow velocity and sensor collisions may compromise $\mathrm{EC} \mathrm{O}_{2}$ exchange rate calculations is illustrated in Fig. 4.

Benthic community light response-The light dependency of the $\mathrm{EC} \mathrm{O}_{2}$ fluxes was evaluated using the photosynthesis vs. irradiance (P-I) relationship (Jassby and Platt 1976). The screened 10 min $\mathrm{EC} \mathrm{O}_{2}$ fluxes covering at least one diel period were averaged down to longer time intervals (1-4 h) to reduce the short-term variability that was independent of the PAR. The averaged fluxes were then plotted against the PAR data. The relationship between the daytime net ecosystem production (NEP; in $\mathrm{mmol} \mathrm{O}_{2} \mathrm{~m}^{-2} \mathrm{~h}^{-1}$ ) and the irradiance (I; in $\mu \mathrm{mol}$ quanta $\mathrm{m}^{-2} \mathrm{~s}^{-1}$ ) was estimated as $\mathrm{NEP}=P_{\mathrm{m}} \tanh \left(I / I_{\mathrm{k}}\right)-R$, where $P_{\mathrm{m}}$ is the maximum rate of gross primary production (GPP; in $\mathrm{mmol} \mathrm{O}_{2} \mathrm{~m}^{-2} \mathrm{~h}^{-1}$ ), $I_{\mathrm{k}}$ is the light saturation parameter (in $\mu \mathrm{mol}$ quanta $\mathrm{m}^{-2} \mathrm{~s}^{-1}$ ), and $R$ is the nighttime respiration term (in $\mathrm{mmol}$ $\mathrm{O}_{2} \mathrm{~m}^{-2} \mathrm{~h}^{-1}$ ). The fitting parameters $P_{\mathrm{m}}, I_{\mathrm{k}}$, and $R$ were allowed to vary until a least-squares line of best fit to the data was obtained. This simple model adequately fit all the data sets and in most cases showed a remarkably tight fit to the measured EC data (see below). The compensation irradiance $\left(I_{\mathrm{c}}\right.$, in $\mu \mathrm{mol}$ quanta $\left.\mathrm{m}^{-2} \mathrm{~s}^{-1}\right)$ was subsequently derived from the P-I curves as the $x$-intercept.

Rates of benthic productivity-The rates of benthic productivity were calculated from each time series of the $\mathrm{EC} \mathrm{O}_{2}$ exchange rates. Nighttime periods were identified as the periods when no response of the $\mathrm{EC} \mathrm{O}_{2}$ exchange to the available PAR could be observed. The PAR threshold used to define nighttime periods was within the range of

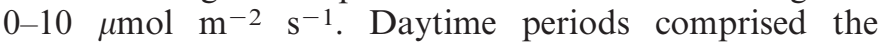


remaining intervals. Gaps in the data that occurred as a result of the flux screening process were filled with modeled fluxes based on the P-I relationship. The NEP and R were then derived from the gap-filled time series in mmol $\mathrm{O}_{2}$ $\mathrm{m}^{-2} \mathrm{~h}^{-1}$ as a bulk average of the $\mathrm{O}_{2}$ fluxes during the daytime and nighttime, respectively. Assuming a lightindependent respiration rate we also estimated the benthic GPP (in $\mathrm{mmol} \mathrm{O}_{2} \mathrm{~m}^{-2} \mathrm{hr}^{-1}$ ) as GPP $=\mathrm{NEP}+|\mathrm{R}|$.

The autotrophic-heterotrophic balance of the benthic ecosystem (termed "net ecosystem metabolism" [NEM], in mmol m-2 $\mathrm{d}^{-1}$ ) was derived as a weighted average of the NEP and R fluxes. The NEM indicated whether sediment $\mathrm{O}_{2}$ production through photosynthesis balanced the various heterotrophic processes that directly or indirectly consume $\mathrm{O}_{2}$. Positive NEM values indicated a net $\mathrm{O}_{2}$ release by the benthic ecosystem (autotrophy) while negative NEM values indicated a net $\mathrm{O}_{2}$ uptake (heterotrophy) over a $24 \mathrm{~h}$ period.

\section{Results}

Metadata-This study is based on 18 EC deployments that in total integrate $750 \mathrm{~h}$ of measuring time divided between the shallow-water stations. During the study the salinity in the bottom waters ranged from 28.3 to 33.3 and the bottom-water temperature ranged from $5.5^{\circ} \mathrm{C}$ during the summer to $-1.4^{\circ} \mathrm{C}$ during the winter. Changes in temperature and salinity during the individual deployments were minimal. Integrated downwelling PAR measured in situ ranged from $14,105 \mathrm{mmol}$ quanta $\mathrm{m}^{-2} \mathrm{~d}^{-1}$ in the summer to $103 \mathrm{mmol}$ quanta $\mathrm{m}^{-2} \mathrm{~d}^{-1}$ in the winter. The bottom water was on average supersaturated with $\mathrm{O}_{2}$ during the summer (up to 127\%) and undersaturated during the winter (down to 92\%; Table 1).

EC fluxes-The EC $\mathrm{O}_{2}$ flux time series typically exhibited a distinct diel structure in response to the availability of PAR (Fig. 5). Elevated PAR during the daytime typically resulted in positive $\mathrm{EC}_{2}$ fluxes and a gradual increase in $\mathrm{O}_{2}$ concentration in the bottom water. Nighttime periods were characterized by negative $\mathrm{EC} \mathrm{O}_{2}$ fluxes. The two main drivers of the EC-resolved $\mathrm{O}_{2}$ exchange rates were the light (PAR) availability and the flow velocity at the seabed (Figs. 5, 6). The benthic communities exhibited high photosynthetic efficiency. The P-I relationship (Fig. 6; Table 2) demonstrated that little light was required to drive an autotrophic response and the benthic communities quickly became light saturated. Photoinhibition was not observed in any of the 18 data sets.

The diel signal in the data was overlain with short-term variability, seen in the 10 min EC exchange measurements in Figs. 5, 6. As an example, an increase in the flow from 2 to $12 \mathrm{~cm} \mathrm{~s}^{-1}$ during the day enhances the $\mathrm{EC} \mathrm{O}_{2}$ exchange by 3.5 times, from 2.1 to $7.4 \mathrm{mmol} \mathrm{O} \mathrm{m}^{-2} \mathrm{~h}^{-1}$. Similarly an increase in flow from 2 to $8 \mathrm{~cm} \mathrm{~s}^{-1}$ during the night enhances the rate of $\mathrm{O}_{2}$ exchange from -0.1 to $-2.7 \mathrm{mmol}$ $\mathrm{O}_{2} \mathrm{~m}^{-2} \mathrm{~h}^{-1}$ (Fig. 6). Although the short-term variability of the EC exchange rates with flow does not necessarily scale with metabolic processes in the sediment, rates that are integrated over longer time periods provide robust mea-

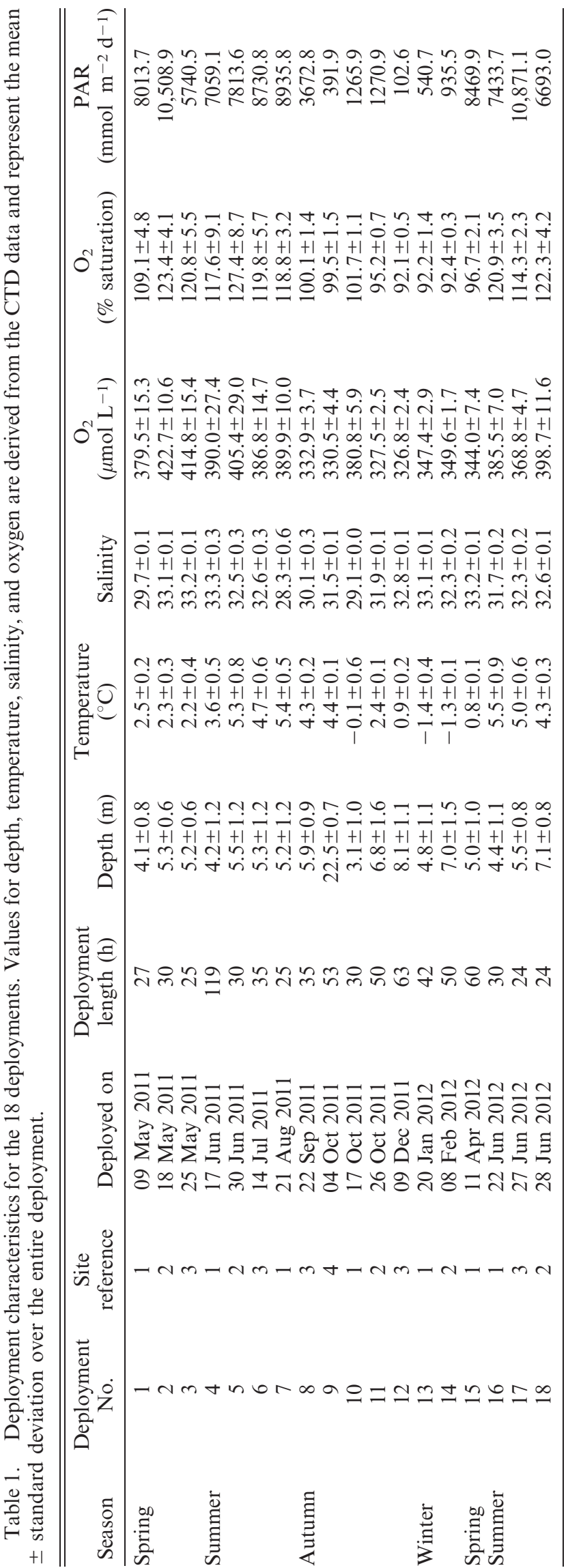



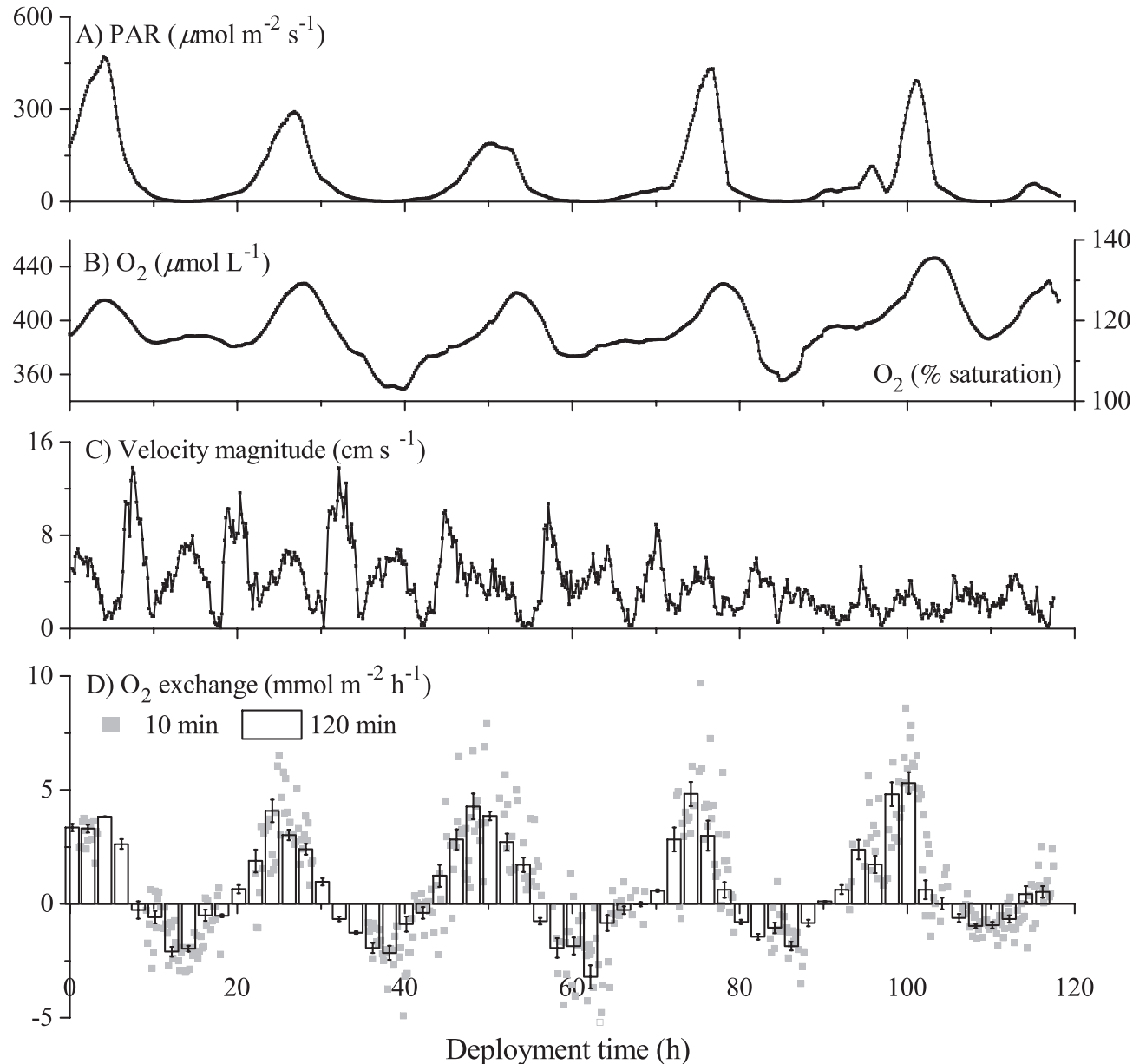

Fig. 5. As a typical data example, a 5 d long EC data set from site 1 in June 2011 (deployment 4). (D) The EC $\mathrm{O}_{2}$ exchange rates are presented in $10 \mathrm{~min}$ (gray points) and $2 \mathrm{~h}$ averages (bars). The $2 \mathrm{~h}$ averages are presented \pm standard error (SE; $n=12)$. Gaps in the $10 \mathrm{~min}$ data are periods that have been excluded due to the screening process (see Methods). Gaps that altogether constituted $<20 \%$ of the data were filled with modeled fluxes based on the P-I relationship. (A) A distinct diel cycle in the $\mathrm{O}_{2}$ exchange rates is observed in response to the available PAR. Positive $\mathrm{O}_{2}$ fluxes indicate a net $\mathrm{O}_{2}$ production (autotrophic) and negative $\mathrm{O}_{2}$ fluxes indicate a net $\mathrm{O}_{2}$ consumption (heterotrophic) benthic ecosystem. (C) The flow velocity affected the EC exchange rates during both day and night.

sures of the benthic $\mathrm{O}_{2}$ exchange rates and therefore the rate of carbon turnover-see Discussion.

Rates of benthic $\mathrm{O}_{2}$ exchange-We derived robust measurements for NEP, R, NEM, and GPP over the year from the high-quality EC measurements at the four sites as evidence for an active and productive phototrophic benthic community (Fig. 7; Table 2). The highest rates of $\mathrm{O}_{2}$ exchange were observed during the spring and summer months. Sites 1 and 2 were autotrophic during these periods, while site 3 was heterotrophic. In all cases a substantial primary production was detected. Rates for benthic GPP were highly variable between the three sites during the spring and summer, ranging from 0.63 to $5.68 \mathrm{mmol} \mathrm{O} \mathrm{O}_{2} \mathrm{~m}^{-2} \mathrm{~h}^{-1}$. Site 1 was overall the most productive of the three sites during the spring and summer, with a combined 2011 and 2012 average rate of GPP of 2.99 $\pm 1.96 \mathrm{mmol} \mathrm{O}_{2} \mathrm{~m}^{-2} \mathrm{~h}^{-1}$ (mean \pm standard deviation [SD], $n=5)$. For site 2 it was $1.48 \pm 0.51 \mathrm{mmol} \mathrm{O}_{2} \mathrm{~m}^{-2} \mathrm{~h}^{-1}$ (mean $\pm \mathrm{SD}, n=3$ ) and for site 3 it was $1.26 \pm 0.49 \mathrm{mmol}$ $\mathrm{O}_{2} \mathrm{~m}^{-2} \mathrm{~h}^{-1}$ (mean $\pm \mathrm{SD}, n=3$ ). The combined 2011 and 2012 average benthic GPP rate for the three sites during spring and summer was $2.11 \pm 1.54 \mathrm{mmol} \mathrm{O}_{2} \mathrm{~m}^{-2} \mathrm{~h}^{-1}$ (mean $\pm \mathrm{SD}, n=11$ ).

High average rates of GPP up to $1.28 \mathrm{mmol} \mathrm{O}_{2} \mathrm{~m}^{-2} \mathrm{~h}^{-1}$ were maintained during the early autumn. Under greatly reduced light availability during the late-autumn and winter period (up to 100 times lower integrated PAR fluxes compared to the spring and summer months), the benthic primary production was significantly reduced, but benthic phototrophs were still active. Light levels of $5 \mu \mathrm{mol}$ quanta $\mathrm{m}^{-2} \mathrm{~s}^{-1}$ or less often resulted in an autotrophic response (Table 2; Fig. 8). The highest rates of GPP during this period were measured at site 2 in February 2012 

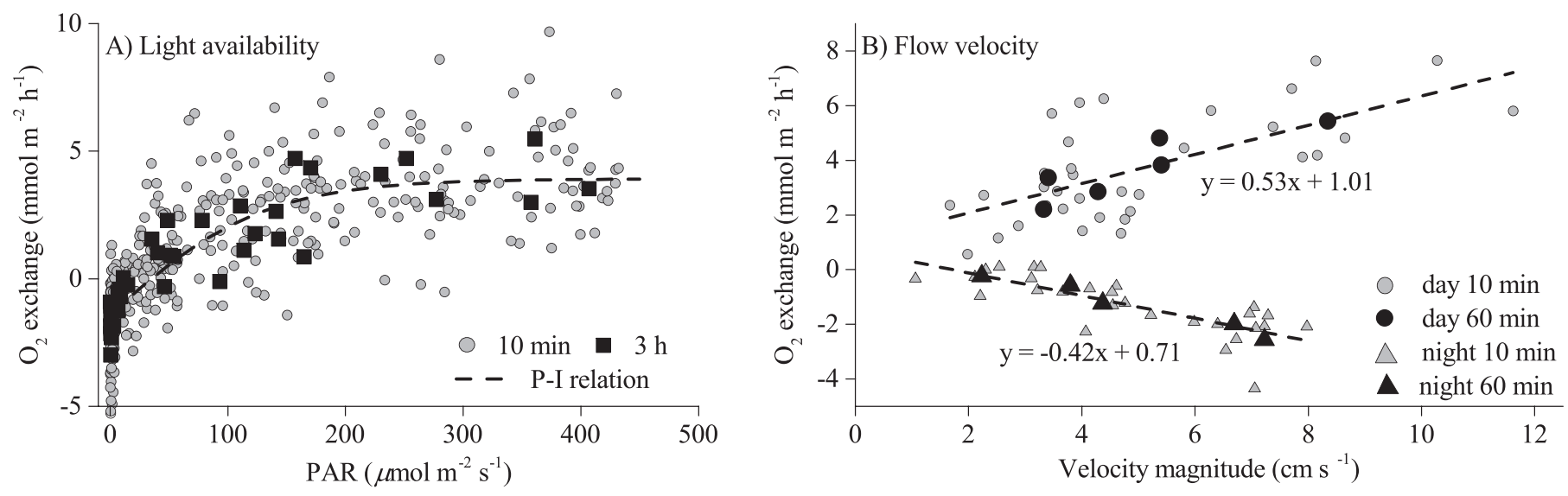

Fig. 6. The two main EC $\mathrm{O}_{2}$ exchange drivers were (A) the light availability and (B) the flow velocity magnitude. The P-I relationship is from a $120 \mathrm{~h}$ deployment from site 1 in June 2011 (deployment 4; Fig. 5). The P-I model (broken line) is fit to the $3 \mathrm{~h}$ flux averages using a least-squares fit. Averaging of the $\mathrm{EC} \mathrm{O}_{2}$ exchange rates markedly increased the coefficient of determination $\left(R^{2}=0.36\right.$ and 0.73 for the $10 \mathrm{~min}$ and $3 \mathrm{~h}$ flux averages, respectively) but did not result in significant changes in the estimated maximum photosynthetic rate $\left(P_{\mathrm{m}}\right)$, the light saturation parameter $\left(I_{\mathrm{k}}\right)$, or the respiration parameter $(R)$ that are derived from the fit. Panel B shows a typical relationship between the flow velocity and the $\mathrm{EC}_{2}$ exchange rates during night and day at site 1 (deployment 4). A linear regression is fitted to the $10 \mathrm{~min}$ exchange rates to illustrate the effect of a flow increase or decrease on the EC $\mathrm{O}_{2}$ exchange rate. An increase in the flow from 2 to $12 \mathrm{~cm} \mathrm{~s}^{-1}$ during the day enhances the $\mathrm{EC} \mathrm{O}_{2}$ exchange by 3.5 times, from 2.1 to $7.4 \mathrm{mmol} \mathrm{O}_{2} \mathrm{~m}^{-2} \mathrm{~h}^{-1}\left(R^{2}\right.$ $=0.43$ ). Similarly, an increase in flow from 2 to $8 \mathrm{~cm} \mathrm{~s}^{-1}$ during the night enhances the rate of $\mathrm{O}_{2}$ exchange from -0.1 to $-2.7 \mathrm{mmol} \mathrm{O}_{2}$ $\mathrm{m}^{-2} \mathrm{~h}^{-1}\left(R^{2}=0.58\right)$. The closed symbols are $1 \mathrm{~h}$ averages $\pm \mathrm{SE}(n=6)$.

(deployment 14), with an average rate of $0.93 \mathrm{mmol} \mathrm{O}_{2}$ $\mathrm{m}^{-2} \mathrm{~h}^{-1}$ for the $50 \mathrm{~h}$ deployment. However, during peak irradiance, GPP rates were seen to be around $1.8 \mathrm{mmol} \mathrm{O}_{2}$ $\mathrm{m}^{-2} \mathrm{~h}^{-1}$ (Fig. 8). The late-autumn and winter average rate for the three sites (deployments 11 through 14) was $0.65 \pm$ $0.56 \mathrm{mmol} \mathrm{O}_{2} \mathrm{~m}^{-2} \mathrm{~h}^{-1}$ (mean $\left.\pm \mathrm{SD}, n=4\right)$. Although all of our data sets in the late autumn and winter suggest autotrophic conditions during the daytime, the periods with adequate levels of PAR were restricted to only a few hours per day (Table 2; Figs. 7, 8). As a result, when integrated over $24 \mathrm{~h}$, the three sites were heterotrophic or at metabolic balance during the late-autumn and winter period (range from 0.8 to $-2.7 \mathrm{mmol} \mathrm{O}_{2} \mathrm{~m}^{-2} \mathrm{~d}^{-1}$; Table 2).

To demonstrate the benthic phototrophic potential of deeper waters a single $53 \mathrm{~h}$ deployment was carried out at $22 \mathrm{~m}$ water depth in October 2011 (deployment 9; Fig. 8). The average $I_{\mathrm{c}}$ for this deployment was $4.3 \mu \mathrm{mol}$ quanta $\mathrm{m}^{-2} \mathrm{~s}^{-1}$, which was the lowest of the 18 deployments. The rate of GPP was comparable to that observed at the shallow-water stations during the winter $\left(0.73 \mathrm{mmol} \mathrm{O}_{2}\right.$ $\left.\mathrm{m}^{-2} \mathrm{~h}^{-1}\right)$.

\section{Discussion}

Benthic primary production - We observed a substantial benthic primary production in four contrasting benthic habitats in a Greenland fjord over the year. Sites 1 and 2 were autotrophic during the spring and summer, with NEM rates of up to $43.6 \mathrm{mmol} \mathrm{O}_{2} \mathrm{~m}^{-2} \mathrm{~d}^{-1}$. Site 3 was heterotrophic year-round, with NEM rates increasing in magnitude with the transition from winter $\left(-1.6 \mathrm{mmol} \mathrm{O}_{2}\right.$ $\left.\mathrm{m}^{-2} \mathrm{~d}^{-1}\right)$ to summer $\left(-12.3 \mathrm{mmol} \mathrm{O}_{2} \mathrm{~m}^{-2} \mathrm{~d}^{-1}\right)$. Measurements by Glud et al. (2010) in nearby embayments in spring 2009 using the EC method suggest an average GPP rate of
$1.13 \mathrm{mmol} \mathrm{O} \mathrm{m}^{-2} \mathrm{~h}^{-1}\left(27 \mathrm{mmol} \mathrm{O}_{2} \mathrm{~m}^{-2} \mathrm{~d}^{-1}\right)$, which falls within the range of values obtained by our more comprehensive study ( 0.63 to $5.68 \mathrm{mmol} \mathrm{O}_{2} \mathrm{~m}^{-2} \mathrm{~h}^{-1}$ ). Although greatly reduced, benthic GPP during the late autumn and winter was detectable in all cases, ranging from 0.05 to $1.28 \mathrm{mmol} \mathrm{O}_{2} \mathrm{~m}^{-2} \mathrm{~h}^{-1}$. Benthic communities inhabiting deeper waters showed capabilities similar to the winter communities. Despite peak downwelling irradiances of $<20 \mu \mathrm{mol}$ quanta $\mathrm{m}^{-2} \mathrm{~s}^{-1}$, the $\mathrm{EC} \mathrm{O}_{2}$ exchange rates demonstrate a well-acclimated phototrophic community capable of efficiently photosynthesizing at very low light levels.

Early estimates compiled by Cahoon (1999) suggest very modest rates of benthic primary production in the Arctic region (defined as $60-90^{\circ}$ latitudes) with an average value of $\sim 3.7 \mathrm{mmol} \mathrm{m}^{-2} \mathrm{~d}^{-1}$ for the $0-5 \mathrm{~m}$ depth range. A more recent review by Glud et al. (2009) considered a broader database for the Arctic. From this the authors argue that the rates presented by Cahoon (1999) most likely underestimate the true rates by 5-10 times. Our derived rate estimate for benthic GPP of $31.6 \mathrm{mmol} \mathrm{m} \mathrm{m}^{-2} \mathrm{~d}^{-1}$ is consistent with this observation (Table 2). This finding suggests that the difference in benthic GPP rates between the Arctic and lower latitudes as compiled by Cahoon (1999) could be due to undersampling rather than true latitudinal-related gradients. Furthermore, given the potential for benthic primary production in the extensive shelf areas of the Arctic (Gattuso et al. 2006), benthic primary production could become quantitatively more important for sustaining shallow-water food webs under future scenarios of reduced sea ice cover during summer (Glud et al. 2009).

Rates of benthic GPP that are derived from $\mathrm{O}_{2}$ exchange measurements assume equal $\mathrm{O}_{2}$ consumption during the day and night. However, $\mathrm{O}_{2}$ consumption during the 


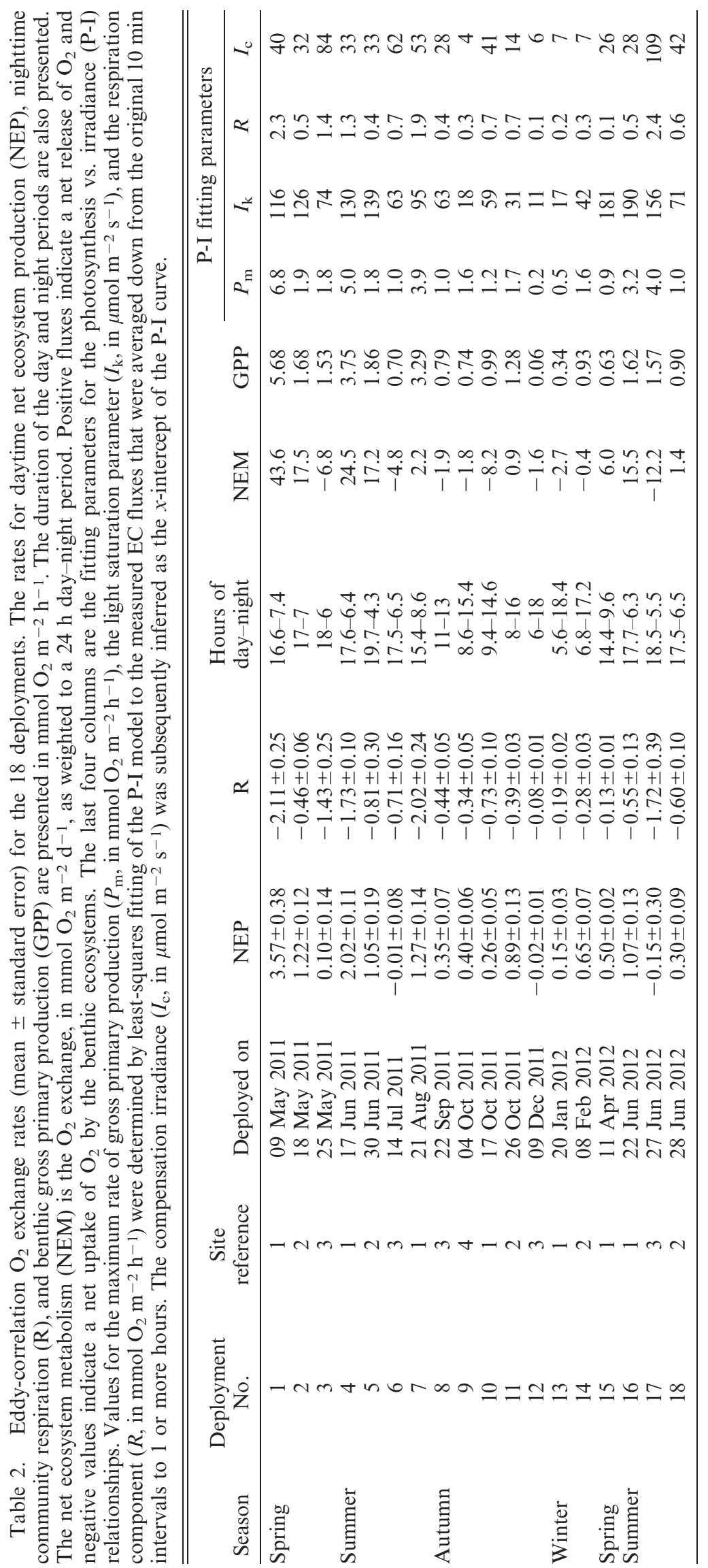




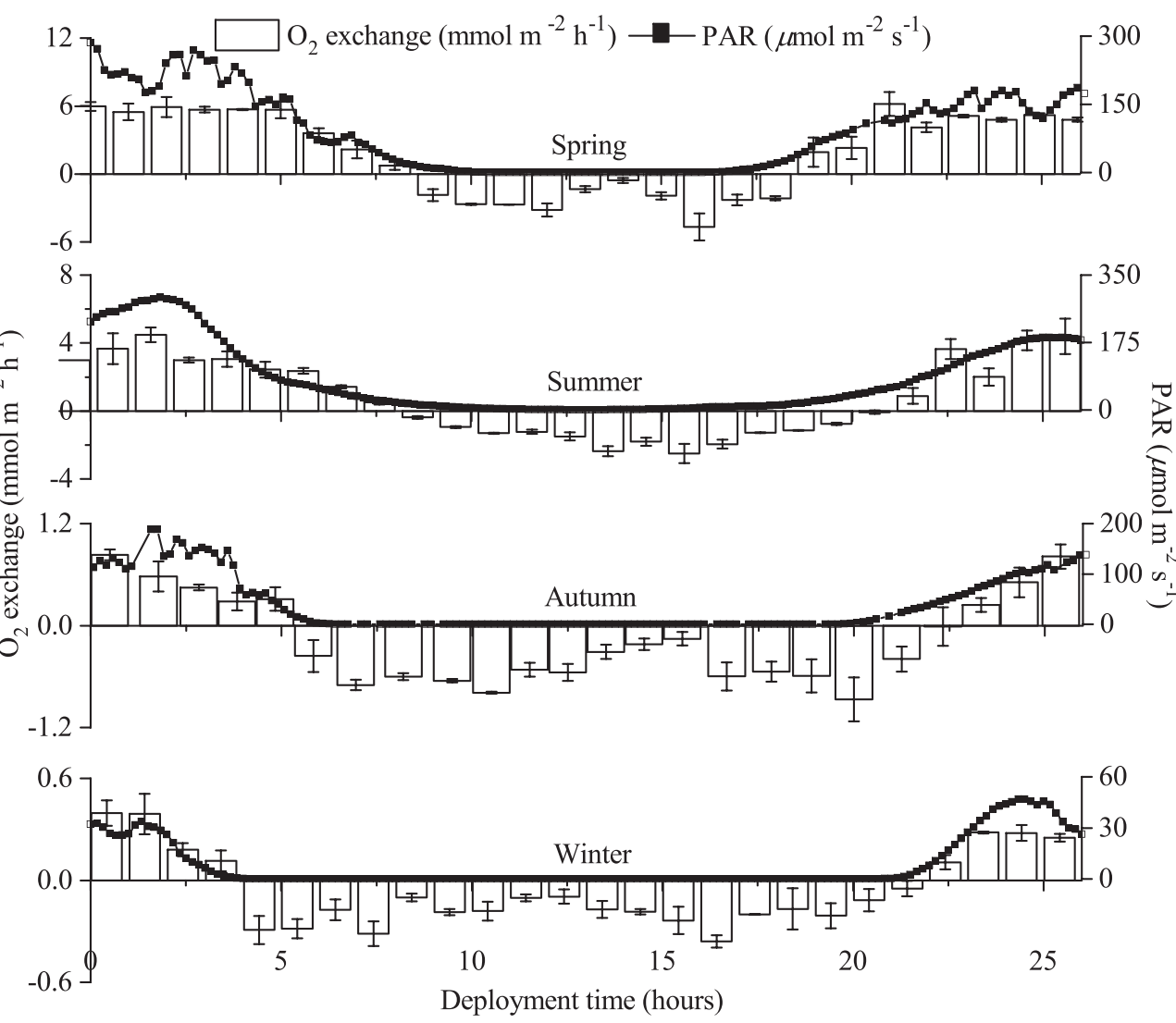

Fig. 7. Diel time series of $\mathrm{EC} \mathrm{O}_{2}$ exchange rates (presented in $1 \mathrm{~h}$ averages $\pm \mathrm{SE} ; n=6$ ) from each season at site 1 (spring $=$ deployment 1 , summer $=$ deployment 4 , autumn $=$ deployment 10 , winter $=$ deployment 13 ). Note that the scales on the $y$-axes are different for the different plots to better illustrate the detail. Despite strong seasonal variances of in situ irradiance the benthic communities were autotrophic year-round during the daytime.

daytime typically exceeds nighttime $\mathrm{O}_{2}$ consumption by up to 1.8 times (Fenchel and Glud 2000) as a result of deeper $\mathrm{O}_{2}$ penetration during the daytime (hence a larger volume of sediment that can support aerobic mineralization), and an enhanced microbial turnover of leached labile photosynthesates (Epping and Jørgensen 1996; Fenchel and Glud 2000). Therefore, rates of benthic GPP derived from $\mathrm{O}_{2}$ exchange rates most likely underestimate the true activity. Albeit conservative, the average areal rate of benthic GPP of $138 \mathrm{~g} \mathrm{C} \mathrm{m}^{-2} \mathrm{yr}^{-1}$ is 1.4 times higher than the 2006 2011 mean depth-integrated gross pelagic production of the $\sim 30-60 \mathrm{~m}$ deep photic zone of the region as assessed by in situ $\mathrm{H}^{14} \mathrm{CO}_{3}^{-}$incubations $\left(96 \mathrm{~g} \mathrm{C} \mathrm{m}^{-2} \mathrm{yr}^{-1}\right.$; Rysgaard et al. 2012). On an ecosystem level, benthic photosynthesis therefore contributes significantly to primary production in the fjord and may serve as the main food source for shallow-water macrofauna communities. Benthic fauna are an important pathway for the turnover of carbon and on average account for 25-50\% of the total benthic $\mathrm{O}_{2}$ uptake in shallow waters (Glud 2008). The fauna-mediated $\mathrm{O}_{2}$ uptake (FOU) is partitioned between the respiration of the organisms, which constitutes $\sim 20-40 \%$ of the FOU, and the stimulated microbial-mediated respiration and reoxidation following fauna irrigation and sediment reworking (Glud 2008). The urchin S. droebachiensis is the dominant macrobenthic species in waters shallower than $20 \mathrm{~m}$ in the Kobbefjord region, and its carbon demand for depths of $\sim 5 \mathrm{~m}$ at site 3 has been estimated at $\sim 61 \mathrm{~g} \mathrm{C} \mathrm{m}^{-2} \mathrm{yr}^{-1}$ (Blicher et al. 2009). Our estimates for benthic primary production of $138 \mathrm{~g} \mathrm{C} \mathrm{m}^{-2} \mathrm{yr}^{-1}\left(11.5 \mathrm{~mol} \mathrm{O}_{2} \mathrm{~m}^{-2} \mathrm{yr}^{-1}\right)$ point towards the benthic phototrophic compartment as an important year-round nutritional source for the macrobenthic fauna in the fjord.

Drivers of EC-resolved $\mathrm{O}_{2}$ fluxes-Light availability: The availability of light at the sediment surface is the primary requirement for benthic photosynthesis, since the supply of nutrients is usually maintained by organic matter mineralization processes within the sediment (Barranguet et al. 1998). The derived P-I relationships (Table 2) clearly reflect a high photosynthetic efficiency of the benthic communities. Even during winter at low light levels, the sediment exhibited a clear light response with $I_{\mathrm{c}}$ values as low as $2 \mu \mathrm{mol}$ quanta $\mathrm{m}^{-2} \mathrm{~s}^{-1}$ and $I_{\mathrm{k}}$ values as low as $11 \mu \mathrm{mol}$ quanta $\mathrm{m}^{-2} \mathrm{~s}^{-1}$. Photoautotrophic communities inhabiting light-limited systems such as high-latitude fjords and continental slopes exhibit very efficient light-harvesting capabilities that allow the communities to persist under greatly reduced irradiances (Kühl et al. 2001; McGee et al. 2008). From the P-I relations we estimate that the benthic 


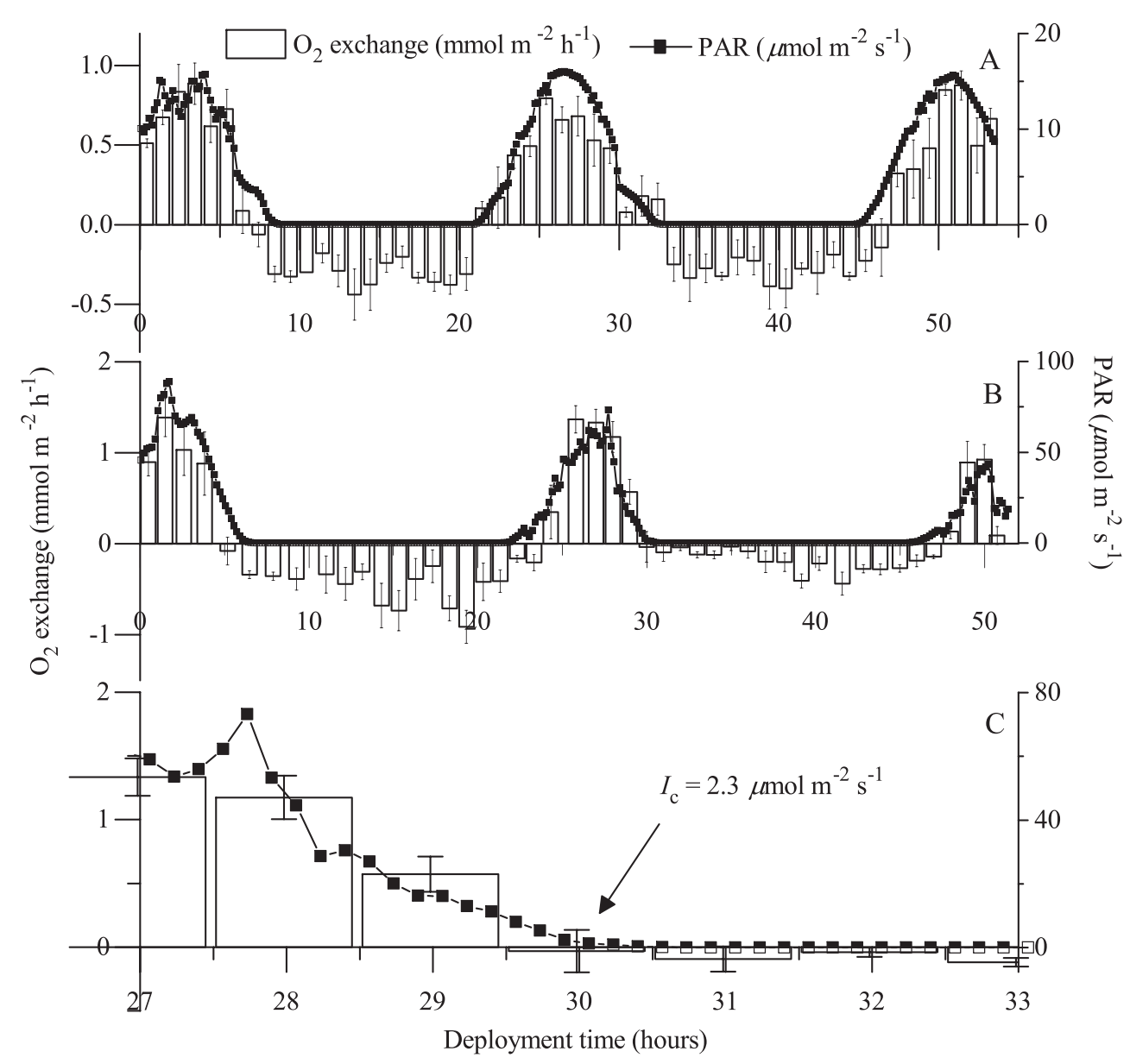

Fig. 8. $\quad \mathrm{EC} \mathrm{O}_{2}$ exchange time series under low light conditions at (A) $22 \mathrm{~m}$ depth during October 2011 (site 4, deployment 9) and (B) at $7 \mathrm{~m}$ depth during February 2012 (site 2, deployment 14). Despite low light, the benthic communities showed high photosynthetic efficiency. Rates of benthic gross primary production of up to $1.7 \mathrm{mmol} \mathrm{O}_{2} \mathrm{~m}^{-2} \mathrm{~h}^{-1}$ were measured during peak irradiance. (C) is a $6 \mathrm{~h}$ section from (B) deployment 14 that illustrates that little light was required to drive an autotrophic response. In this case the estimated compensation irradiance $\left(I_{\mathrm{c}}\right)$ was $2.3 \mu \mathrm{mol} \mathrm{m}{ }^{-2} \mathrm{~s}^{-1}$.

communities at the three sites during the summer were light saturated for $\sim 60 \%$ of the daytime, equivalent to $\sim 40 \%$ of the diel period. Light saturation also persisted during winter, although the short days combined with the low angle of the sun restricted its duration to $\sim 20 \%$ of the diel period.

Detailed studies on the photosynthetic performance of benthic systems indicate a dynamic community of microalgae that actively migrate within the sediment in response to the steep and varying ambient gradients of irradiance (Barranguet et al. 1998; Kromkamp et al. 1998). The dynamic behavior of benthic microalgae allows the community to maintain a high net productivity under prolonged periods of elevated irradiance. Consistent with our observations, net photoinhibition of benthic communities at high irradiance is not often observed in benthic systems.

Rates of benthic primary production showed consistent seasonal trends, with the derived P-I parameters $P_{\mathrm{m}}, I_{\mathrm{k}}$, and $R$ changing with the availability of PAR. The benthic communities therefore exhibited a clear seasonal response in their photosynthetic capabilities. However, substantial variability in the P-I parameters between the sites within the same season and throughout the year is also evident (Fig. 9). There are obvious challenges when attempting to attribute changes in the photosynthetic performances of mixed benthic communities, often having species-specific responses (Kühl et al. 2001), to seasonal environmental variables such as temperature and PAR. We noted a changing macroscopic composition of the benthic phototrophic communities at the shallow sites over the year. In the late-spring and summer months both macroalgae and microalgae were present, whereas during the late autumn and winter macroalgae were largely absent. Previous investigations have shown that the $I_{\mathrm{k}}$ and $P_{\mathrm{m}}$ of benthic communities can vary on timescales of hours and days in response to the changing light conditions (Kühl et al. 2001; Glud et al. 2002). However, overall the derived P-I parameters reflect a net photosynthetic performance typical of polar micro- and macroalgal species (Glud et al. 2009). 


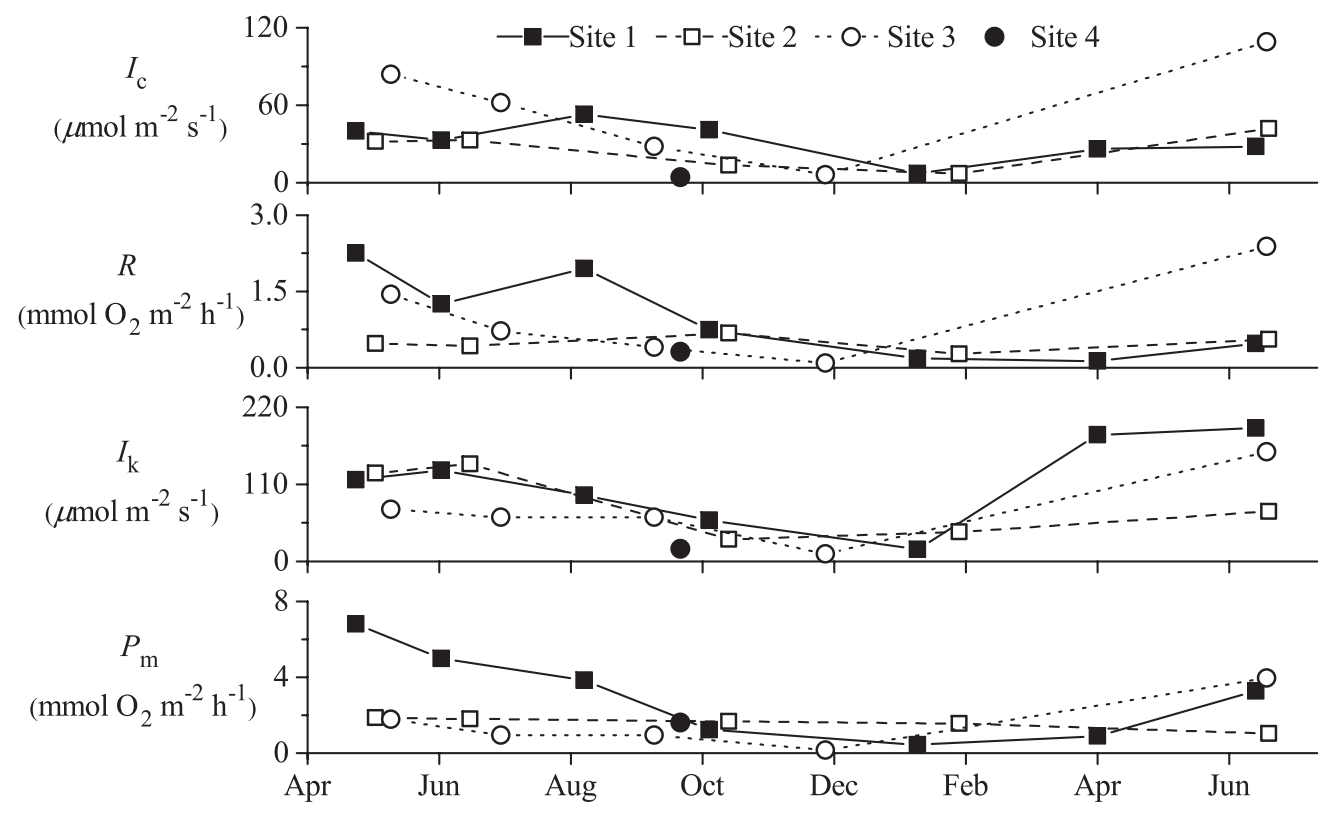

Fig. 9. A time series of the photosynthetic parameters derived from the P-I relationships for the four sites. A seasonal trend in the PI parameters was observed in response to the availability of PAR. The compensation irradiance $\left(I_{\mathrm{c}}\right)$ and light saturation $\left(I_{\mathrm{k}}\right)$ values were low, indicating a benthic community able to photosynthesize efficiently under low light conditions, typical of high-latitude ecosystems.

Flow velocity and $\mathrm{O}_{2}$ concentration within the $B B L$ : The EC measurement theory invokes assumptions that the mean current velocity and $\mathrm{O}_{2}$ concentration within the BBL are at steady state. However, transient flow velocities and $\mathrm{O}_{2}$ concentrations were evident at all four sites investigated. At site 1, rapid increases in the flow velocity magnitude of up to $15 \mathrm{~cm} \mathrm{~s}^{-1}$ over 1 or more hours coincided with a manyfold increase in the $\mathrm{EC} \mathrm{O}_{2}$ exchange rates (Fig. 6). Transient flow velocities and $\mathrm{O}_{2}$ concentrations within the $\mathrm{BBL}$ can induce a temporary bias in the measured $\mathrm{EC} \mathrm{O}_{2}$ exchange rates (Holtappels et al. 2013). To minimize inclusion of low-frequency nonturbulent contributions we derived $\mathrm{EC} \mathrm{O}_{2}$ fluxes over $10 \mathrm{~min}$ intervals. Although we cannot exclude that the fluxes were affected by nonturbulent contributions during certain periods, changes in the mean flow velocity and $\mathrm{O}_{2}$ concentrations typically occurred over longer timescales than this. The criteria we used to evaluate the quality of the 10 min $\mathrm{EC} \mathrm{O}_{2}$ fluxes, in particular the rapid changes in flow direction and the "anisotropic ratio threshold" method (Fig. 4) were effective at identifying periods with uncharacteristically low or high exchange rates of $\mathrm{O}_{2}$ that occur due to insufficient turbulent mixing or non-steady-state conditions within the BBL. The fluxes that fell within these periods (typically amounting to $<20 \%$ of each data set) were discarded and replaced by modeled fluxes based on the P-I relation for subsequent bulk average flux estimates for NEP, R, NEM, and GPP (Table 2). Furthermore, averages derived from long-term deployments such as the ones presented herein integrate much of the site-specific variability and provide trustworthy exchange rates (Holtappels et al. 2013).

Large variations between consecutive 10 min $\mathrm{EC} \mathrm{O}_{2}$ flux estimates were common within the 18 data sets, even during periods of relatively steady flow and $\mathrm{O}_{2}$ concentrations (Figs. 4, 5). Analysis of the $w^{\prime} C^{\prime}$ time series often indicates the presence of a few large positive and negative events within each 10 min interval in which turbulent eddies with timescales of minutes transfer $\mathrm{O}_{2}$ up and down (data not shown). The magnitude and frequency of large events within each 10 min flux interval may vary and subsequently so may the covariance estimate $w^{\prime} C^{\prime}$. Therefore, at these timescales the EC fluxes are naturally variable. Work by McPhee (2008) has documented similar observations for under-ice heat fluxes measured by EC. The typical approach is to average the covariance estimates (in our case, $10 \mathrm{~min}$ ) to $1 \mathrm{~h}$ or more to get an exchange rate that is much better representative of that taking place at the seabed surface.

Even at the hourly resolution a substantial variability in the EC fluxes was evident in our data sets (Figs. 5-8). Detailed studies on the benthic $\mathrm{O}_{2}$ exchange rate have shown it to be highly dynamic. In cohesive sediments or solid interfaces, the thinning of the diffusive boundary layer (DBL) during periods of enhanced flow enhances the $\mathrm{O}_{2}$ exchange (Kühl et al. 1996; Glud et al. 2007). The maximum DBL impedance of an $\mathrm{O}_{2}$-consuming sediment can be approximated by its theoretical elimination according to Boudreau and Guinasso (1982). Elimination of the $350 \mu \mathrm{m}$ thick DBL in $\mathrm{O}_{2}$ microprofiles taken in recovered sediment cores from Nipisat Sound (site 1) during April 2012 enhanced the benthic $\mathrm{O}_{2}$ uptake in the dark by a maximum of 1.3 times, from 1.0 to $1.3 \mathrm{mmol} \mathrm{O}_{2} \mathrm{~m}^{-2} \mathrm{~h}^{-1}$ (data not shown). By contrast, 5-fold increases in the EC $\mathrm{O}_{2}$ fluxes with flow were common (Fig. 6). The DBL thickness may therefore account for an appreciable but modest fraction of the variability observed within the EC $\mathrm{O}_{2}$ fluxes. For highly permeable sediments, advective porewater flows dominate the exchange processes of $\mathrm{O}_{2}$ in the sediment surface layers and may substantially alter the benthic $\mathrm{O}_{2}$ exchange rate (Cook et al. 2007; Berg et al. 
2013). Although the benthic $\mathrm{O}_{2}$ exchange rate is often seen to be highly variable in such systems, the flow-induced variations in the benthic $\mathrm{O}_{2}$ exchange rates do not necessarily scale with the actual sediment $\mathrm{O}_{2}$ turnover rates. The variations may instead reflect the effects of an expanding oxic volume of sediment that can act as an " $\mathrm{O}_{2}$ reservoir," supporting $\mathrm{O}_{2}$ consumption during periods of reduced flow, and characterized by a suppressed benthic $\mathrm{O}_{2}$ exchange rate (Cook et al. 2007). Furthermore, changing pools of organic matter (e.g., photosynthesates) as well as variations in fauna activity could substantially affect $\mathrm{O}_{2}$ uptake rates during certain hours of the diel period (Fenchel and Glud 2000; Wenzhöfer and Glud 2004). Appropriate spatial and temporal integration is therefore required to account for the site-specific natural variability, to provide robust estimates for carbon production and mineralization in coastal benthic environments (Glud 2008).

EC measurements in coastal benthic habitats - The EC method provides the opportunity to investigate complex benthic ecosystems noninvasively. The number of EC studies in coastal environments is likely to increase in the future and, concurrent with the development of faster and more robust sensors (e.g., optical sensors; Chipman et al. 2012), be expanded to resolve fluxes for a broader range of environmental parameters. The following section aims to outline some important considerations for deployment planning and interpretation of EC fluxes in coastal environments.

A main consideration in deployment planning is for the user-defined measurement height above the seabed. Generally, the position best suited for extracting EC measurements is from within the "constant flux" layer within the well-mixed BBL (Brand et al. 2008), typically located 1.5-2 times above the zero plane displacement (Burba 2013). Measurements that are carried out too close to the boundary may instead characterize more localized sources due to bottom features such as stones, plants, and macrofauna, and are therefore not necessarily representative of the benthic ecosystem as a whole.

The selected measurement height has further implications for the size of the EC flux footprint (and therefore the extent to which the benthic communities are well represented within the resolved EC fluxes), as well as the ability to accurately correlate the EC fluxes to environmental variables (e.g., flow velocity, PAR). Evaluating the area of the seabed that is integrated within the $\mathrm{O}_{2}$ exchange measurements is desirable to better interpret EC measurements. While this parameter is well constrained when using benthic chambers and microprofilers, it is much less so for EC measurements. We followed the parameterization of Berg et al. (2007) to estimate the length, width, and the distance of the region that contributes most to the measured EC exchange rates, as a function of the $z_{0}$ and the measurement height above the seabed. The mean $z_{0}$ for the shallow sites ranged from $0.001-0.017 \mathrm{~m}$, resulting in footprint lengths of between $20-74 \mathrm{~m}$ with a width of $\sim 1.6 \mathrm{~m}$ and a region of maximum flux located $0.6-2.5 \mathrm{~m}$ upstream from the EC instrument. Furthermore, we followed the procedure described by Rheuban and Berg (2013) to estimate the potential errors induced due to spatial variability of the benthic communities as well as temporal changes in benthic exchange rates of $\mathrm{O}_{2}$. The uneven distribution of the flux signal within the EC measurement footprint may affect the derived EC exchange rates in heterogeneous benthic environments, such that EC exchange rates may not be representative of the total benthic community. Since the aim of our study was to obtain $\mathrm{EC} \mathrm{O}_{2}$ exchange rates that are representative of the total benthic communities at each of our shallow sites, we evaluated whether our measurement setup was optimal for this purpose. We estimated the heterogeneity of the benthic communities from photo documentation at the four sites, and deduced that under most conditions encountered the spatial scales that were included in the EC measurements were large relative to the spatial scale of variation on the seabed. Therefore, any errors that were induced due to the spatial variability were minimal $(<5 \%)$. This analysis gives us confidence that $\mathrm{EC} \mathrm{O}_{2}$ fluxes we present are representative of the total benthic community at each of the investigated sites.

The selected measurement height also has implications for correlating the $\mathrm{EC} \mathrm{O}_{2}$ fluxes to environmental variables (e.g., PAR). The time required for changes in the benthic $\mathrm{O}_{2}$ exchange rate to be registered at the EC measuring height may be significantly longer than the time window over which the EC fluxes are analyzed, becoming larger as the measurement height increases and the $z_{0}$ decreases (Rheuban and Berg 2013). The range of $z_{0}$ values (0.001$0.017 \mathrm{~m})$ and $C_{D}$ values (0.004-0.023) we estimated indicate rough bed geometry typical of sands, gravels, and cobbles (Reidenbach et al. 2010). A rough bed geometry results in vigorous turbulent mixing that rapidly transports the signal from the seabed to the EC measurement point. As a result, the time required to transport the signal from the seabed to the EC measurement height was for most cases found to be between 10-30 min and in all cases did not exceed $50 \mathrm{~min}$. This time interval is shorter than the $\mathrm{EC} \mathrm{O}_{2}$ exchange average time windows used (i.e., $1-4 \mathrm{~h}$ ) to derive the P-I relationships. In this respect, the P-I parameters presented in Table $2\left(P_{\mathrm{m}}, I_{\mathrm{k}}, R\right)$ therefore reflect accurately correlated $\mathrm{EC} \mathrm{O}_{2}$ fluxes with PAR. Further confirmation of this was inferred by deriving P-I relations from EC fluxes averaged over time windows ranging from $10 \mathrm{~min}$ to several hours, which indicated that the P-I parameters remained largely unaffected by the time-averaging window (see Fig. 4).

The high quality of data presented in this study along with the detailed inferences on the biological performance of the benthic communities that we were able to derive from these measurements gives us confidence that the EC method can provide robust benthic exchange rates in heterogeneous benthic communities under changing environmental conditions, provided that careful consideration is given to deployment planning and data analysis.

\section{Acknowledgments}

We thank Anni Glud, Heidi L. Sørensen, Lorenz Meire, Lars Heilmann, Flemming Heinrich, Thomas Krogh, Martin E. Blicher, Thomas-Juul Pedersen, Ivali Lennert, Kunuk Lennert, 
and Knud Kreutzmann for technical and/or field assistance, as well as Lorenzo Rovelli and Kasper Hancke for discussions on topics related to this manuscript. We thank Cynthia Bluteau and Andreas Lorke for providing routines for calculating the inertial dissipation and planar rotation, respectively. We thank Peter Berg and a second anonymous reviewer for constructive comments that improved this manuscript. This project was financed by the Commission for Scientific Research in Greenland (KVUG; GCRC6507), the U.K. Natural Environmental Research Council (NERC, NE/F018612/1, NE/F0122991/1, NE/G006415/1), the European Research Council through an Advanced Grant (ERC2010-AdG20100224), the Canada Excellence Research Chair program, and the Danish National Research Foundation (DNRF53).

\section{References}

Barranguet, C., J. Kromkamp, and J. Peene. 1998. Factors controlling primary production and photosynthetic characteristics of intertidal microphytobenthos. Mar. Ecol. Prog. Ser. 173: 117-126, doi:10.3354/meps 173117

Berg, P., H. Roy, F. Janssen, V. Meyer, B. B. Jorgensen, M. Huettel, AND D. DE BeER. 2003. Oxygen uptake by aquatic sediments measured with a novel non-invasive eddy correlation technique. Mar. Ecol. Prog. Ser. 261: 75-83, doi:10. 3354/meps261075

— $\longrightarrow$, AND P. L. Wiberg. 2007. Eddy correlation flux measurements: The sediment surface area that contributes to the flux. Limnol. Oceanogr. 52: 1672-1684, doi:10.4319/ 10.2007.52.4.1672

—, AND OTHERS. 2013. Eddy correlation measurements of oxygen fluxes in permeable sediments exposed to varying current flow and light. Limnol. Oceanogr. 58: 1329-1343.

Blicher, M. E., L. M. Rasmussen, M. K. Sejr, F. R. Merkel, AND S. RYSGaARD. 2011. Abundance and energy requirements of eiders (Somateria spp.) suggest high predation pressure on macrobenthic fauna in a key wintering habitat in SW Greenland. Polar Biol. 34: 1105-1116, doi:10.1007/s00300011-0968-3

—, M. K. Sejr, and S. Rysgaard. 2009. High carbon demand of dominant macrozoobenthic species indicates their central role in ecosystem carbon flow in a sub-Arctic fjord. Mar. Ecol. Prog. Ser. 383: 127-140, doi:10.3354/meps07978

Bluteau, C. E., N. L. Jones, and G. N. Ivey. 2011. Estimating turbulent kinetic energy dissipation using the inertial subrange method in environmental flows. Limnol. Oceanogr.: Methods 9: 302-321, doi:10.4319/lom.2011.9.302

Boudreau, B. P., And N. L. Guinasso. 1982. The influence of a diffusive sublayer on aggregation, dissolution and diagenesis at the sea floor, p. 115-145. In K. A. Fanning and M. Manheim [eds.], The dynamic environment of the seafloor. Lexington.

Brand, A., D. F. McGinnis, B. Wehrli, and A. Wüest. 2008. Intermittent oxygen flux from the interior into the bottom boundary of lakes as observed by eddy correlation. Limnol. Oceanogr. 53: 1997-2006, doi:10.4319/lo.2008.53.5.1997

Burba, G. 2013. Eddy covariance method for scientific, industrial, agricultural, and regulatory applications: A field book on measuring ecosystem gas exchange and areal emission rates. LI-COR Biosciences.

CAhoon, L. B. 1999. The role of benthic microalgae in neritic ecosystems. Oceanogr. Mar. Biol. Annu. Rev. 37: 47-86.

Chipman, L., M. Huettel, P. Berg, V. Meyer, I. Klimant, R. N. Glud, And F. Wenzhoefer. 2012. Oxygen optodes as fast sensors for eddy correlation measurements in aquatic systems. Limnol. Oceanogr.: Methods 10: 304-316, doi:10.4319/ lom.2012.10.304
Cook, P. L. M., F. Wenzhöfer, R. N. Glud, F. Janssen, and M Huettel. 2007. Benthic solute exchange and carbon mineralization in two shallow subtidal sandy sediments: Effect of advective pore-water exchange. Limnol. Oceanogr. 52: 1943-1963, doi:10.4319/1o.2007.52.5.1943

DAlsgaARD, T. 2003. Benthic primary production and nutrient cycling in sediments with benthic microalgae and transient accumulation of macroalgae. Limnol. Oceanogr. 48: 2138-2150, doi:10.4319/1o.2003.48.6.2138

Epping, E. H. G., AND B. B. JørGensen. 1996. Light-enhanced oxygen respiration in benthic phototrophic communities. Mar. Ecol. Prog. Ser. 139: 193-203, doi:10.3354/meps139193

Fenchel, T., AND R. N. Glud. 2000. Benthic primary production and $\mathrm{O}_{2}-\mathrm{CO}_{2}$ dynamics in a shallow-water sediment: Spatial and temporal heterogeneity. Ophelia 53: 159-171.

Gattuso, J. P., B. Gentili, C. M. Duarte, J. A. Kleypas, J. J. Middelburg, And D. Antoinne. 2006. Light availability in the coastal ocean: Impact on the distribution of benthic photosynthetic organisms and their contribution to primary production. Biogeosciences 3: 489-513, doi:10.5194/bg-3-4892006

Glud, R. N. 2008. Oxygen dynamics of marine sediments. Mar. Biol. Res. 4: 243-289, doi:10.1080/17451000801888726 , P. Berg, H. Fossing, and B. B. Jørgensen. 2007. Effect of the diffusive boundary layer (DBL) on the benthic mineralization and $\mathrm{O}_{2}$ distribution: A theoretical modelling exercise. Limnol. Oceanogr. 52: 547-557, doi:10.4319/lo.2007. 52.2 .0547

,, A. Hume, P. Batty, M. E. Blicher, K. Lennert, AND S. RysGAARD. 2010. Benthic oxygen exchange across hard bottom substrates quantified by eddy correlation in a subArctic fjord. Mar. Ecol. Prog. Ser. 417: 1-12, doi:10.3354/ meps08795

—, M. KÜHL, F. WenZhÖFER, AND S. RysGaARD. 2002. Benthic diatoms of a high Arctic fjord (Young Sound, NE Greenland): Importance for ecosystem primary production. Mar. Ecol. Prog. Ser. 238: 15-29, doi:10.3354/meps238015

-, J. Woelfel, U. Karsten, M. Kuhl, and S. Rysgaard. 2009. Benthic microalgal production in the Arctic: Applied methods and status of the current database. Bot. Mar. 52: 559-571, doi:10.1515/BOT.2009.074

Holtappels, M., R. N. Glud, D. Donis, B. Liu, A. Hume, F. Wenzhoefer, AND M. Kuypers. 2013. Effect of transient bottom water currents and oxygen concentrations on benthic exchange rates as assessed by eddy correlation measurements. J. Geophys. Res.: Oceans 118: 1157-1169, doi:10.1002/ jgrc. 20112

Hume, A. C., P. Berg, and K. J. McGlathery. 2011. Dissolved oxygen fluxes and ecosystem metabolism in an eelgrass (Zostera marina) meadow measured with the eddy correlation technique. Limnol. Oceanogr. 56: 86-96, doi:10.4319/ lo.2011.56.1.0086

Jahnke, R. A., J. R. Nelson, R. L. Marinelli, and J. E. Eckman. 2000. Benthic flux of biogenic elements on the Southeastern US continental shelf: Influence of pore water advective transport and benthic microalgae. Cont. Shelf Res. 20: 109-127, doi:10.1016/S0278-4343(99)00063-1

Jassby, A. D., And T. Platt. 1976. Mathematical formulation of relationship between photosynthesis and light for phytoplankton. Limnol. Oceanogr. 21: 540-547, doi:10.4319/ lo.1976.21.4.0540

Kromkamp, J., C. Barranguet, and J. Peene. 1998. Determination of microphytobenthos PSII quantum efficiency and photosynthetic activity by means of variable chlorophyll fluorescence. Mar. Ecol. Prog. Ser. 162: 45-55, doi:10.3354/ meps 162045 
Kühl, M., R. N. Glud, J. Borum, R. Roberts, and S. RysgaArd. 2001. Photosynthetic performance of surface-associated algae below sea ice as measured with a pulse-amplitude-modulated (PAM) fluorometer and $\mathrm{O}_{2}$ microsensors. Mar. Ecol. Prog. Ser. 223: 1-14, doi:10.3354/meps223001 H. Ploug, and N. B. Ramsing. 1996. Microenvironmental control of photosynthesis and photosynthesiscoupled respiration in an epilithic cyanobacterial biofilm. J. Phycol. 32: 799-812, doi:10.1111/j.0022-3646.1996.00799.x

Long, M. H., P. Berg, D. de Beer, and J. C. Zieman. 2013. In situ coral reef oxygen metabolism: An eddy correlation study. PLoS One 8: e58581, doi:10.1371/journal.pone.0058581

, D. Koopmans, P. Berg, S. Rysgaard, R. N. Glud, and D. H. SøgaARD. 2012. Oxygen exchange and ice melt measured at the ice-water interface by eddy correlation. Biogeosciences 9: 1957-1967, doi:10.5194/bg-9-1957-2012

Lorke, A., D. F. McGinnis, And A. Maeck. 2013. Eddycorrelation measurements of benthic fluxes under complex flow conditions: Effects of coordinate transformations and averaging time scales. Limnol. Oceanogr.: Methods 11: 425-437, doi:10.4319/lom.2013.11.425

Lorrai, C., D. F. McGinnis, P. Berg, A. Brand, and A. Wüest. 2010. Application of oxygen eddy correlation in aquatic systems. J. Atmos. Oceanic Technol. 27: 1533-1546, doi:10.1175/2010JTECHO723.1

McGee, D., R. A. Laws, and L. B. Cahoon. 2008. Live benthic diatoms from the upper continental slope: Extending the limits of marine primary production. Mar. Ecol. Prog. Ser. 356: $103-112$, doi: $10.3354 /$ meps 07280

McGinnis, D. F., P. Berg, A. Brand, C. Lorrai, T. J. Edmonds, AND A. WÜEST. 2008. Measurements of eddy correlation oxygen fluxes in shallow freshwaters: Towards routine applications and analysis. Geophys. Res. Lett. 35: L04403, doi:10.1029/2007GL032747

—, AND OTHERS. 2011. Simple, robust eddy correlation amplifier for aquatic dissolved oxygen and hydrogen sulfide flux measurements. Limnol. Oceanogr.: Methods 9: 340-347, doi:10.4319/lom.2011.9.340

McPhee, M. 2008. Air-ice-ocean interaction: Turbulent ocean boundary layer exchange processes. Springer.
Middelburg, J. J., And K. Soetaert. 2004. The role of sediments in shelf ecosystem dynamics, p. 353-375. In K. H. B. Allan and R. Robinson [eds.], The global coastal ocean. Harvard Univ. Press.

Mori, N., T. Suzuki, And S. Kakuno. 2007. Noise of acoustic Doppler velocimeter data in bubbly flow. J. Eng. Mech. 133: 122-125, doi:10.1061/(ASCE)0733-9399(2007)133:1(122)

Reidenbach, M. A., P. Berg, A. Hume, J. C. R. Hansen, and E. R. Whitman. 2013. Hydrodynamics of intertidal oyster reefs: The influence of boundary layer flow processes on sediment and oxygen exchange. Limnol. Oceanogr.: Fluids and Environments 3: 225-239, doi:10.1215/21573689-2395266

-, H. Limm, M. Hondzo, and M. T. Stacey. 2010. Effects of bed roughness on boundary layer mixing and mass flux across the sediment-water interface. Water Resour. Res. 46: W07530, doi:10.1029/2009WR008248

Revisbech, N. P. 1989. An oxygen microelectrode with a guard cathode. Limnol. Oceanogr. 34: 474-478, doi:10.4319/ 10.1989.34.2.0474

Rheuban, J. E., and P. Berg. 2013. The effects of spatial and temporal variability at the sediment surface on aquatic eddy correlation flux measurements. Limnol. Oceanogr.: Methods 11: 351-359, doi:10.4319/lom.2013.11.351

RYSGAARD, S., AND OTHERs. 2012. High air-sea $\mathrm{CO}_{2}$ uptake rates in nearshore and shelf areas of Southern Greenland: Temporal and spatial variability. Mar. Chem. 128-129: 26-33, doi:10.1016/j.marchem.2011.11.002

Wassmann, P., C. M. Duarte, S. Agusti, and M. K. Sejr. 2011. Footprints of climate change in the Arctic marine ecosystems. Global Change Biol. 17: 1235-1249, doi:10.1111/j.13652486.2010.02311.x

Wenzhöfer, F., And R. N. Glud. 2004. Small-scale spatial and temporal variability in coastal benthic $\mathrm{O}_{2}$ dynamics: Effects of fauna activity. Limnol. Oceanogr. 49: 1471-1481, doi:10.4319/ 1o.2004.49.5.1471

Associate editor: Alexander D. Huryn

Received: 25 December 2013 Accepted: 12 May 2014 Amended: 22 May 2014 